\title{
Airborne wind lidar observations over the North Atlantic in 2016 for the pre-launch validation of the satellite mission Aeolus
}

\author{
Oliver Lux, Christian Lemmerz, Fabian Weiler, Uwe Marksteiner, Benjamin Witschas, Stephan Rahm, \\ Andreas Schäfler, and Oliver Reitebuch
}

Deutsches Zentrum für Luft- und Raumfahrt e.V. (DLR), Institut für Physik der Atmosphäre, Oberpfaffenhofen 82234, Germany

Correspondence: Oliver Lux (oliver.lux@dlr.de)

Received: 18 January 2018 - Discussion started: 22 January 2018

Revised: 7 May 2018 - Accepted: 23 May 2018 - Published: 11 June 2018

\begin{abstract}
In preparation of the satellite mission Aeolus carried out by the European Space Agency, airborne wind lidar observations have been performed in the frame of the North Atlantic Waveguide and Downstream Impact Experiment (NAWDEX), employing the prototype of the satellite instrument, the ALADIN Airborne Demonstrator (A2D). The direct-detection Doppler wind lidar system is composed of a frequency-stabilized Nd:YAG laser operating at $355 \mathrm{~nm}$, a Cassegrain telescope and a dual-channel receiver. The latter incorporates a Fizeau interferometer and two sequential Fabry-Pérot interferometers to measure line-of-sight (LOS) wind speeds by analysing both Mie and Rayleigh backscatter signals. The benefit of the complementary design is demonstrated by airborne observations of strong wind shear related to the jet stream over the North Atlantic on 27 September and 4 October 2016, yielding high data coverage in diverse atmospheric conditions. The paper also highlights the relevance of accurate ground detection for the Rayleigh and Mie response calibration and wind retrieval. Using a detection scheme developed for the NAWDEX campaign, the obtained ground return signals are exploited for the correction of systematic wind errors. Validation of the instrument performance and retrieval algorithms was conducted by comparison with DLR's coherent wind lidar which was operated in parallel, showing a systematic error of the A2D LOS winds of less than $0.5 \mathrm{~m} \mathrm{~s}^{-1}$ and random errors from 1.5 (Mie) to $2.7 \mathrm{~m} \mathrm{~s}^{-1}$ (Rayleigh).
\end{abstract}

\section{Introduction}

Over the last decade, Doppler wind lidar systems (Reitebuch, 2012a) have emerged as a versatile tool for the rangeresolved detection of wind shears (Shangguan et al., 2017), aircraft wake vortices (Köpp et al., 2004; Dolfi-Bouteyre et al., 2009), wind and temperature turbulence (Banakh et al., 2014) and gravity waves (Witschas et al., 2017), amongst other applications. In particular, direct-detection wind lidars have been demonstrated to provide accurate wind information from ground up to altitudes of $60 \mathrm{~km}$ (Dou et al., 2014) or even beyond (Baumgarten, 2010; Hildebrand et al., 2012). The most ambitious endeavour in this context is the upcoming satellite mission Aeolus of the European Space Agency (ESA), which strives for the continuous global observation of atmospheric wind profiles employing the first ever satelliteborne Doppler wind lidar instrument ALADIN (Atmospheric LAser Doppler INstrument) (ESA, 2008; Stoffelen et al., 2005). Being a part of ESA's Living Planet Programme, Aeolus will significantly contribute to the improvement in numerical weather prediction (NWP), as it will support to close the gap in wind profile data coverage, especially over the oceans, which has been identified as one of the major deficiencies in the current Global Observing System (Baker et al., 2014; Andersson, 2016). For this purpose, it will provide one line-ofsight (LOS) component of the horizontal wind vector from ground throughout the troposphere up to the lower stratosphere (about $27 \mathrm{~km}$ ) with a vertical resolution of 0.25 to $2 \mathrm{~km}$, depending on altitude and precision of 1 to $3 \mathrm{~m} \mathrm{~s}^{-1}$ (ESA, 2016; Reitebuch, 2012b). The obtained data will allow for greater accuracy of the initial atmospheric state in NWP models and thus improve the quality of weather fore- 
casts (Tan and Andersson, 2005) as well as the understanding of atmospheric dynamics and climate processes (ESA, 2008). As a secondary product, the wind lidar system, which is scheduled for launch in 2018, will provide information on cloud top heights and on the vertical distribution of clouds and aerosol properties such as backscatter and extinction coefficients (Flamant et al., 2008; Ansmann et al., 2007).

Over the past years, a prototype of the Aeolus payload, the ALADIN Airborne Demonstrator (A2D), has been developed and deployed in several field experiments, aiming at pre-launch validation of the satellite instrument and at performing wind lidar observations under various atmospheric conditions (Reitebuch et al., 2009; Marksteiner et al., 2011, 2017). Most recently, in autumn of 2016, the A2D was employed in the frame of the North Atlantic Waveguide and Downstream Impact Experiment (NAWDEX) (Schäfler et al., 2018). Based in Keflavík, Iceland, this international field campaign had the overarching goal to investigate the influence of diabatic processes, related to clouds and radiation, on the evolution of the North Atlantic jet stream. Accurate wind speed observations of the North Atlantic jet stream form the basis for quantifying effects of disturbances for downstream propagation and related high-impact weather in Europe. For this purpose, four research aircraft equipped with diverse payloads were employed, which allowed for the observation of a large set of atmospheric parameters using a multitude of state-of-the-art remote sensing instruments, while ground stations delivered a comprehensive suite of additional measurements to complement the meteorological analysis.

With a view to the forthcoming Aeolus mission, the NAWDEX campaign was an ideal platform for extending the wind data set obtained with the A2D, as it offered the opportunity to perform wind measurements in dynamically complex scenes, including strong wind shear and varying cloud conditions. Furthermore, multiple instrument calibrations, which are a prerequisite for accurate wind retrieval, could be conducted over ice, namely the Vatnajökull glacier in Iceland, ensuring high signal-to-noise ratios (SNR) of the ground return and thus low systematic errors. In addition, the large-scale cooperation of atmospheric research groups from around the world was beneficial for the preparation of the upcoming launch of Aeolus.

Among the 14 research flights conducted in the frame of NAWDEX, the two flights performed on 27 September and on 4 October 2016 were especially interesting with regard to the instrument-driven goals of the campaign. While the former flight was characterized by exceptionally high wind speeds and strong wind shear to be sampled by the A2D, the latter one provided ground visibility which allowed for the analysis of ground return signals. In general, analysis of the ground return offers many possibilities for improving the performance of lidar instruments. Recently, Amediek and Wirth (2017) introduced a method for quantifying laser pointing uncertainties in airborne and spaceborne lidar instruments which is based on the comparison of ground el- evations derived from the lidar ranging data with elevation data from a high-resolution digital elevation model (DEM). Regarding airborne wind lidar and radar systems, ground echoes can be exploited to account for systematic pointing errors and to determine the mounting angles of the instrument. Here, the ground surface is used as a zero wind reference, which allows us to estimate the contribution of the aircraft motion to the actual atmospheric wind measurement and hence to correct for inaccuracies in the aircraft attitude data as well as in the instrument's alignment (Bosart et al., 2002; Kavaya et al., 2014; Chouza et al., 2016a; Weiler, 2017). Accurate zero wind correction (ZWC), however, requires precise differentiation between atmospheric and ground return signals in order to prevent systematic errors. This is particularly true for the A2D (and ALADIN) due to its coarse vertical resolution of several hundred metres. Hence, in contrast to previous $\mathrm{A} 2 \mathrm{D}$ airborne campaigns, an enhanced scheme for the detection of ground return signals was developed for NAWDEX.

The paper is organized as follows. First, the operation principle of the system is described with a focus on the complementary design of the instrument comprising two different receiver channels, which allow for the analysis of both particle and molecular backscatter signals. The subsequent section is devoted to the Rayleigh and Mie response calibrations, which represent an essential part of the data analysis. Here, the implemented ground detection method used for the A2D data analysis is introduced. Comparison with the approach taken in previous campaigns reveals the influence of the surface albedo on the quality of Rayleigh and Mie response calibrations and highlights the necessity of proper ground detection. Afterwards, wind observations performed with the A2D during the two above-mentioned NAWDEX flights are presented, demonstrating the ability of the lidar system to provide wind profiles with broad data coverage under various atmospheric conditions. Evaluation of the data accuracy and precision is conducted by comparing the measured wind speeds with those obtained by DLR's coherent wind lidar system (Weissmann et al., 2005; Witschas et al., 2017), which was operated in parallel from the same aircraft as a reference system. Finally, ZWC based on the refined ground detection scheme is shown to provide a significant reduction of the systematic wind error for the second flight.

\section{The A2D direct-detection wind lidar system}

The A2D wind lidar is composed of a pulsed, frequencystable, ultraviolet (UV) laser transmitter incorporating a reference laser system, a Cassegrain telescope, a configuration of optical elements (front optics) to spatially overlap a small portion of the outgoing radiation with the return signals from the atmosphere and the ground, and a dual-channel receiver including detectors. A schematic of the lidar is depicted in 


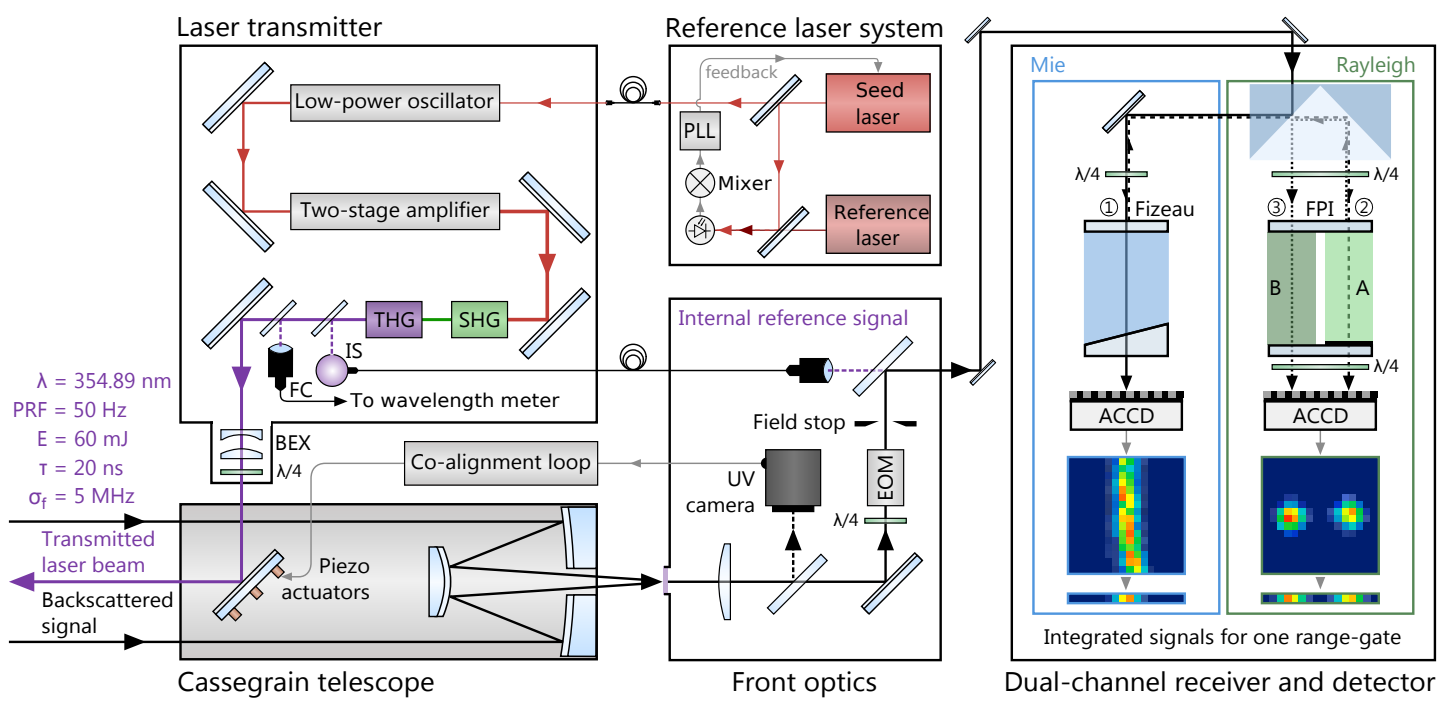

Figure 1. Schematic of the ALADIN Airborne Demonstrator (A2D) wind lidar instrument consisting of an injection-seeded, frequencytripled laser transmitter, a Cassegrain telescope, front optics and a dual-channel receiver. PLL: phase locked loop; SHG: second harmonic generator; THG: third harmonic generator; IS: integrating sphere; FC: fibre coupler; BEX: beam expander; EOM: electro-optic modulator; FPI: Fabry-Pérot interferometer; ACCD: accumulation charge-coupled device.

Fig. 1. The individual components will be described in the following.

\subsection{Laser transmitter, telescope and front optics}

The laser transmitter of the A2D is based on a frequencytripled Nd:YAG master oscillator power amplifier (MOPA) system, generating $20 \mathrm{~ns}$ pulses (full width at half maximum, FWHM) at $354.89 \mathrm{~nm}$ wavelength. The injectionseeded laser, which uses an active frequency stabilization technique, provides single-frequency UV pulses with energy of $60 \mathrm{~mJ}$ at $50 \mathrm{~Hz}$ repetition rate $(3.0 \mathrm{~W}$ average power), while showing near-diffraction-limited beam quality. Concerning the spectral characteristics, the bandwidth of the transmitted UV laser pulses is $50 \mathrm{MHz}$ (FWHM), while the pulse-to-pulse frequency stability is approximately $3 \mathrm{MHz}$ (root mean square). A comprehensive description of the laser transmitter configuration and its performance is provided in Lemmerz et al. (2017) and Schröder et al. (2007).

In the last years, particular attention has been devoted to the cavity control mechanism which ensures high singlefrequency operation stability even under vibration conditions. In addition to the strict requirements in terms of frequency stability, a further challenge is imposed by the necessity to trigger the receiver electronics about $60 \mu$ s before the laser pulse emission with an error of less than $100 \mathrm{~ns}$. Therefore, a dedicated active frequency stabilization technique was developed which is based on the ramp-delay-fire method (Nicklaus et al., 2007). Fast detection of the master oscillator cavity resonances with the seed laser frequency enabled effective compensation of higher-frequency vibrations, while providing a sufficiently early trigger for the detector electronics with a timing stability of around $80 \mathrm{~ns}$ (Lemmerz et al., 2017). The long lead time of the detector electronics is due to an electronic preconditioning process of the accumulating charged-coupled device (ACCD) arrays described in Sect. 2.2. Although ACCDs of the same type are used for the satellite instrument, the preconditioning process is not an issue here, since the round-trip laser pulse travel time from the satellite to the first atmospheric range gate $(\approx 2.5 \mathrm{~ms})$ is sufficiently long.

Measurement of the transmitted laser frequency and calibration of the frequency-dependent transmission of the receiver spectrometers are prerequisite for accurate wind retrieval. Therefore, a small portion of the pulsed UV laser radiation, referred to as internal reference, is collected by an integrating sphere, coupled into a multi-mode fibre $(200 \mu \mathrm{m}$ core diameter) and guided to the receiver via the front optics, while allowing adjustable signal levels by using a variable fibre attenuator (not shown in Fig. 1). Another small fraction of the beam is directed to a wavelength meter (HighFinesse, WS Ultimate 2) with a relative accuracy of $10^{-8}$ in order to monitor the UV frequency of the outgoing laser pulse.

The spatial properties of the high-energy laser were characterized prior to the NAWDEX campaign according to the ISO 11146 standard (ISO, 2005), yielding a beam quality factor $\left(M^{2}\right)$ of 1.1 for both the major and minor beam axis. As a result, after passing through the beam expander, the collimated beam showed a full-angle divergence $( \pm 3 \sigma$, containing $>99 \%$ of the energy) of 98 and $102 \mu \mathrm{rad}$ at $4 \sigma$ beam diameters of 7.3 and $7.1 \mathrm{~mm}$ for the two axes.

The UV laser is transmitted into the atmosphere via a piezo-electrically controlled mirror that is attached to the frame of a Cassegrain-type telescope, as shown in Fig. 1. 
In contrast to ALADIN that incorporates a $1.5 \mathrm{~m}$ diameter telescope and will operate at an off-nadir pointing angle of $35^{\circ}$, the A2D employs a $0.2 \mathrm{~m}$ telescope which is oriented at an off-nadir angle of $20^{\circ}$. The convex spherical secondary mirror of the telescope collects the backscattered light and guides it to the front optics of the A2D receiver assembly. The structural design of the telescope causes a rangedependent overlap function which has to be considered in the wind retrieval as it reduces the backscatter signal (Paffrath, 2006; Paffrath et al., 2009).

Aside from a narrowband UV bandpass filter (FWHM: $1.0 \mathrm{~nm}$ ) which blocks the broadband solar background spectrum, the front optics include an electro-optic modulator (EOM). The EOM is used to avoid saturation of the ACCD by shutting the atmospheric path for several $\mu$ after transmission of the laser pulse, thus preventing strong backscattered light produced close to the instrument (up to about $1 \mathrm{~km}$ ) from being incident on the detectors. In this way, the EOM temporally separates the atmospheric signal from the internal reference signal. The latter is injected into the front optics assembly via the aforementioned multi-mode fibre, so that both signals enter the spectrometer optics on equal paths. In addition, active stabilization of the laser beam pointing is realized by a co-alignment control loop. For this purpose, a portion of the backscattered signal passing through the front optics is imaged onto a UV camera (SONY XC-EU50CE) to monitor the horizontal and vertical position of the centre of gravity $(\mathrm{CoG})$ of the beam. A reference position $\left(\mathrm{CoG}_{X} / \mathrm{CoG}_{Y}\right)$ is defined and a feedback loop involving three piezo-actuators mounted on the last laser transmit mirror is applied to actively stabilize the co-alignment of the transmit and receive path of the laser beam. In this way, variations in the incidence angle of the atmospheric return signals on the receiver spectrometers are reduced. This is crucial for accurate wind measurements, especially for the Rayleigh channel, as angular variations of $1 \mu \mathrm{rad}$ with respect to the $200 \mathrm{~mm}$ telescope diameter and a field of view (FOV) of $100 \mu \mathrm{rad}$ introduce errors of the horizontal wind speeds of up to $0.4 \mathrm{~m} \mathrm{~s}^{-1}$, as derived from optical simulations and experiments (DLR, 2016). It should be noted that active stabilization of the transmitreceive co-alignment is not required for the satellite instrument, since the same telescope is used for transmission of the laser beam and reception of the backscattered signals.

\subsection{Dual-channel receiver and detectors}

The receiver optics of both the satellite instrument and the A2D are almost identical and consist of two different spectrometers, as shown on the right-hand side of Fig. 1. Two sequential Fabry-Pérot interferometers (FPIs) are employed for measuring the Doppler frequency shift of the broadband Rayleigh backscatter signal from molecules, whereas a Fizeau interferometer is used for determining the Doppler shift of the narrowband Mie signal originating from cloud and aerosol backscattering. Detection of the two signals is realized by using two ACCDs which allow for data acquisition in 24 range gates, where the vertical resolution within one profile can be varied from $296 \mathrm{~m}$ to about $2 \mathrm{~km}$.

The wind measurement principle of the A2D wind lidar system is based on detecting frequency differences between the emitted and the backscattered laser pulses. Due to the Doppler effect, the frequency $f_{0}$ of the outgoing pulse is shifted upon backscattering from particles (cloud droplets, aerosols) and molecules which move with the ambient wind. The frequency shift in the backscattered signal $\Delta f_{\text {Doppler }}$ is proportional to the wind speed $v_{\text {LOS }}$ along the laser beam LOS: $\Delta f_{\text {Doppler }}=2 f_{0} / c \cdot v_{\text {LOS }}$, with $c$ being the speed of light. For an emission frequency of $f_{0}=844.75 \mathrm{THz}$ (354.89 nm vacuum wavelength), a LOS wind speed of $1 \mathrm{~m} \mathrm{~s}^{-1}$ translates to a frequency shift of $5.63 \mathrm{MHz}$ which corresponds to a wavelength shift of $2.37 \mathrm{fm}$. The required accuracy of the frequency measurement is hence on the order of $10^{-8}$ to measure wind speeds with an accuracy of $1 \mathrm{~m} \mathrm{~s}^{-1}$. Owing to the large difference in spectral width of the Mie $(\sim 50 \mathrm{MHz})$ and Rayleigh $(\sim 3.8 \mathrm{GHz}$ at $355 \mathrm{~nm}$ and $293 \mathrm{~K})$ atmospheric backscatter signals, two different techniques are applied for deriving the Doppler frequency shift from the two spectral contributions separately.

The measurement principle of the Rayleigh channel relies on the double-edge technique (Chanin et al., 1989; Garnier and Chanin, 1992; Flesia and Korb, 1999; Gentry et al., 2000) and involves two bandpass filters (A and B) which are placed symmetrically around the frequency of the emitted laser pulse, as illustrated in Fig. 2a. The width and spacing of the filter transmission curves (free spectral range (FSR): $10.95 \mathrm{GHz}$, FWHM: $1.78 \mathrm{GHz}$, spacing: $6.18 \mathrm{GHz}$ ) is chosen such that the maxima are close to the inflexion points (edges) of the molecular line that is spectrally broadened by virtue of Rayleigh-Brillouin scattering (Witschas, 2011a, b, c). The transmitted signal through each filter is proportional to the convolution of the respective filter transmission function and the line shape function of the atmospheric backscatter signal. Consequently, the contrast between the return signals $I_{\mathrm{A}}$ and $I_{\mathrm{B}}$ transmitted through filters $\mathrm{A}$ and $\mathrm{B}$ represents a measure of the frequency shift between the emitted and backscattered laser pulse, thus defining the frequency-dependent Rayleigh response $\Psi_{\text {Ray }}$ as follows:

$\Psi_{\text {Ray }}(f)=\frac{I_{\mathrm{A}}(f)-I_{\mathrm{B}}(f)}{I_{\mathrm{A}}(f)+I_{\mathrm{B}}(f)}$.

Close to the filter cross point, where the transmission functions intersect, the relationship between Rayleigh response and frequency is approximately linear with a slope of about $5 \times 10^{-4} \mathrm{MHz}^{-1}$.

The determination of the Doppler shift from the narrowband Mie return signal is based on the fringe-imaging technique (McKay, 2002) involving the measurement of the spatial location of an interference pattern, as shown in Fig. 2b. For this purpose, a Fizeau interferometer is used consisting of two plane plates that are tilted by a small wedge angle of sev- 


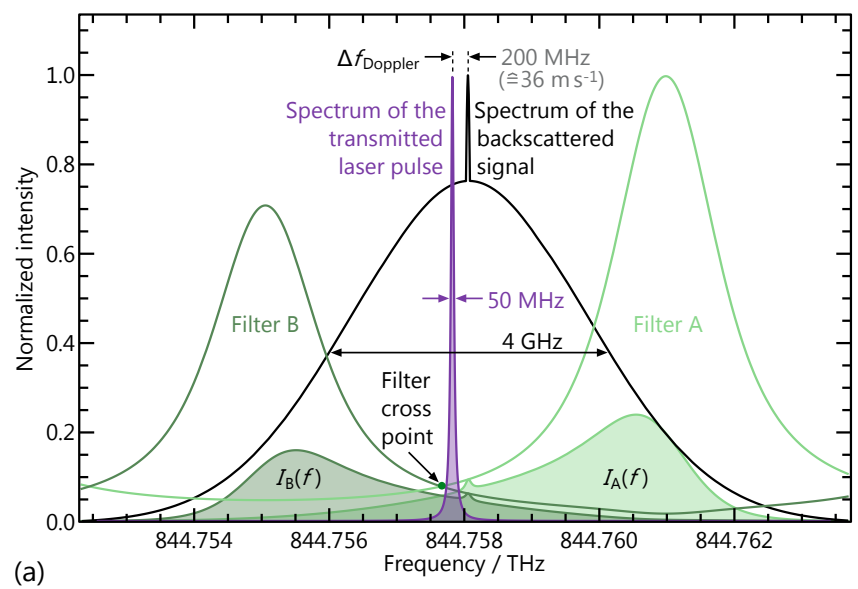

(a)

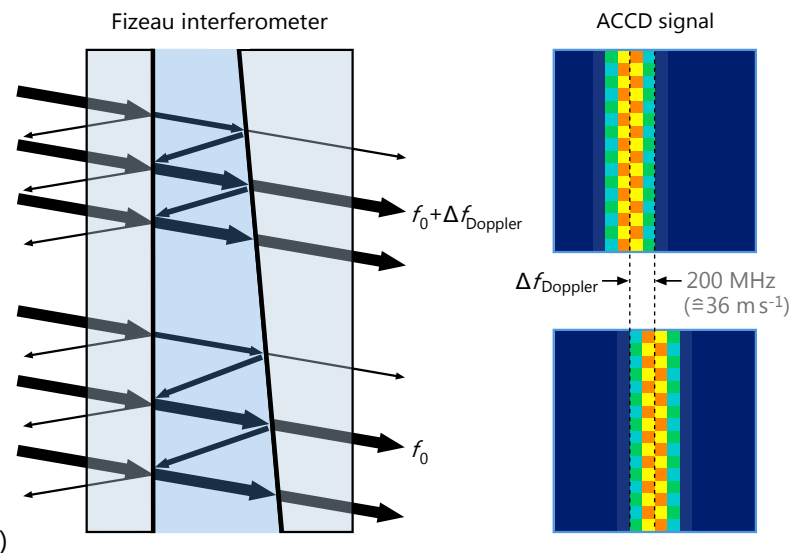

Figure 2. (a) Spectral distribution of the transmitted laser pulse (purple) and the backscattered signal (black), which is composed of the narrowband Mie and the broadband Rayleigh component. The transmission spectra of the two FPI filters of the Rayleigh channel are shown in green, while the filled areas illustrate the respective intensities $I_{\mathrm{A}}(f)$ and $I_{\mathrm{B}}(f)$ transmitted through the filters $\mathrm{A}$ and $\mathrm{B}$ for determining the Doppler shift. (b) Operation principle of the Mie channel based on the fringe-imaging technique.

eral $\mu \mathrm{rad}$ with respect to each other. Due to the wedge angle, the linear interference pattern (fringe) is produced at a distinct lateral position along the wedge where the condition for constructive interference is fulfilled. Hence, a Doppler frequency shift of the signal results in a spatial displacement of the fringe which is vertically imaged onto the ACCD detector, whereby the relationship between the Doppler shift and the centroid position of the fringe $x$ is approximately linear ( $\Delta x \approx k \cdot \Delta f_{\text {Doppler }}$ ), so that the Mie response reads

$$
\Psi_{\text {Mie }}(f)=x(f)=x\left(f_{0}\right)+\Delta x(f)=x_{0}+k \cdot \Delta f_{\text {Doppler }} .
$$

Here, $x_{0}$ represents the Mie fringe centroid position at the frequency $f_{0}$ of the emitted laser pulse and is referred to as Mie centre. $\Delta x$ is the shift of the Mie fringe centroid position with respect to the Mie centre and $k$ denotes the proportionality factor between the Doppler frequency shift $\Delta f_{\text {Doppler }}$ and the resulting shift of the Mie fringe $\Delta x$, thus describing the sensitivity of the Mie channel. The latter is on the order of $k \approx 100 \mathrm{MHz} \mathrm{pixel}^{-1}$. From the Fizeau FSR of $2.2 \mathrm{GHz}$, only a section of $1.6 \mathrm{GHz}$ is recorded by the 16 pixel columns of the ACCD (imaged spectral range), resulting in an effective LOS wind measurement range of $\pm 145 \mathrm{~m} \mathrm{~s}^{-1}$.

The thinned and back-side-illuminated ACCD with $16 \times 16$ pixels is optimized for operation in the UV showing a high quantum efficiency of $85 \%$, while cooling to $-30{ }^{\circ} \mathrm{C}$ provides a low electronic noise level. The electronic charges generated in the imaging zone of the device are accumulated directly in a memory zone within the CCD chip, thus allowing for low readout noise (Reitebuch et al., 2009). For the ACCD used in the Mie channel, the electronic charges of all 16 rows are binned together to one row for each range gate of each laser pulse, resulting in 16 spectral channels of about $100 \mathrm{MHz}$ width. For the Rayleigh channel, the two spots produced by the two FPIs are imaged onto the left and right half of a second ACCD of the same type, with the centres of the spots being separated by 8 pixels (see bottom right part of Fig. 1). As for the Mie channel, the electronic charges of all 16 rows are binned together to one row, whereas the signal of each Rayleigh filter is contained in 6 pixels that are summed up in the retrieval algorithms after digitization.

The memory zone of the ACCD contains 25 rows so that a maximum number of 25 range gates can be acquired, from which three range gates are used for detecting the background light, the detection chain offset (DCO) and the internal reference signal, while two range gates act as buffers for the internal reference. The DCO is a constant electric voltage at the analogue-to-digital converter. The atmospheric backscatter signals are collected in the remaining 20 (socalled atmospheric) range gates. The transfer time from the image to the memory zone limits the minimum temporal resolution of one range gate to $2.1 \mu \mathrm{s}$, which corresponds to a range resolution of $315 \mathrm{~m}$ and a height resolution of $296 \mathrm{~m}$, taking account of the $20^{\circ}$-off-nadir pointing of the instrument. The timing sequences of both ACCDs are programmable, providing flexible and independent vertical resolution for the Rayleigh and Mie wind profiles.

The horizontal resolution of the A2D is determined by the acquisition time of the detection unit. Here, the signals obtained from 20 laser pulses are accumulated to so-called measurements (duration $0.4 \mathrm{~s}$ ), while the combination of the signals from 35 measurements (700 pulses) constitutes one $o b$ servation (duration $14 \mathrm{~s}$ ). Considering the time required for data read out and transfer ( $4 \mathrm{~s})$, the separation time between two subsequent observations thus accounts for $18 \mathrm{~s}$. For a typical ground speed of the Falcon aircraft of $200 \mathrm{~m} \mathrm{~s}^{-1}$, this results in a horizontal resolution of $3.6 \mathrm{~km}$. Note that continuous data readout without gaps of $4 \mathrm{~s}$ is carried out for the satellite instrument on Aeolus, but the concept for on-chip averaging of multiple laser pulse returns to measurements is used as well. In the following, the terms observation and measurement are consistently used referring to the sampling of the A2D data. 
Table 1. Overview of the research flights of the Falcon aircraft conducted in the frame of the NAWDEX campaign and the wind scenes performed with the A2D. The flights on 27 September and 4 October 2016 discussed in the present work are printed in bold. The two flights on 28 September and 15 October 2016 were dedicated to response calibrations of the Rayleigh and Mie channel (see Sect. 3.1), while the first two and the last two flights on 17 September and 18 October 2016 were transfer flights between Oberpfaffenhofen, Germany, and the air base in Keflavík, Iceland.

\begin{tabular}{|c|c|c|c|c|}
\hline $\begin{array}{l}\text { Flight } \\
\text { no. }\end{array}$ & Date & $\begin{array}{r}\text { Flight period } \\
\text { (UTC) }\end{array}$ & $\begin{array}{l}\text { Measurement } \\
\text { period (UTC) }\end{array}$ & $\begin{array}{r}\text { Number of } \\
\text { observations }\end{array}$ \\
\hline \multirow[t]{2}{*}{1} & $17 / 09 / 2016$ & 06:10-08:07 & 06:59-07:12 & 44 \\
\hline & & & $07: 34-07: 45$ & 38 \\
\hline \multirow[t]{3}{*}{2} & $17 / 09 / 2016$ & 10:01-13:33 & $10: 30-11: 31$ & 203 \\
\hline & & & $11: 42-12: 24$ & 140 \\
\hline & & & $12: 43-13: 07$ & 82 \\
\hline \multirow[t]{3}{*}{3} & 21/09/2016 & $14: 00-17: 17$ & $14: 56-15: 27$ & 100 \\
\hline & & & $15: 34-15: 57$ & 78 \\
\hline & & & $16: 11-16: 51$ & 134 \\
\hline \multirow[t]{2}{*}{4} & $23 / 09 / 2016$ & 07:01-10:21 & $07: 51-08: 53$ & 206 \\
\hline & & & 09:14-09:53 & 130 \\
\hline \multirow[t]{2}{*}{5} & 27/09/2016 & 09:28-13:24 & $10: 28-11: 38$ & 234 \\
\hline & & & $11: 48-12: 36$ & 160 \\
\hline 6 & 28/09/2016 & $10: 56-14: 19$ & \multicolumn{2}{|c|}{ Calibration flight } \\
\hline \multirow[t]{3}{*}{7} & 02/10/2016 & 08:31-12:01 & $09: 42-09: 53$ & 38 \\
\hline & & & 10:07-10:47 & 136 \\
\hline & & & 11:06-11:30 & 80 \\
\hline \multirow[t]{3}{*}{8} & $04 / 10 / 2016$ & 08:09-11:43 & 09:00-09:44 & 147 \\
\hline & & & 09:54-10:30 & 121 \\
\hline & & & $10: 35-10: 49$ & 48 \\
\hline \multirow[t]{2}{*}{9} & 04/10/2016 & $13: 04-15: 49$ & $13: 58-14: 51$ & 179 \\
\hline & & & $15: 02-15: 14$ & 41 \\
\hline \multirow[t]{3}{*}{10} & 09/10/2016 & $15: 44-19: 24$ & $16: 41-17: 15$ & 113 \\
\hline & & & $17: 24-17: 54$ & 99 \\
\hline & & & 18:18-18:58 & 138 \\
\hline 11 & $15 / 10 / 2016$ & $10: 05-13: 34$ & $10: 53-11: 07$ & 50 \\
\hline 12 & $15 / 10 / 2016$ & $15: 24-18: 44$ & \multicolumn{2}{|c|}{ Calibration flight } \\
\hline \multirow[t]{2}{*}{13} & $18 / 10 / 2016$ & 08:36-11:14 & 09:20-09:57 & 123 \\
\hline & & & $10: 24-10: 37$ & 45 \\
\hline 14 & $18 / 10 / 2016$ & $12: 39-14: 30$ & $13: 33-13: 53$ & 67 \\
\hline
\end{tabular}

\section{Response calibrations and ground detection}

The A2D direct-detection wind lidar system was employed during the NAWDEX field experiment delivering valuable data with a view to the pre-launch activities for the upcoming Aeolus mission as well as with regards to the meteorological objectives of the campaign. In the framework of NAWDEX, 14 research flights have been performed with the Falcon aircraft of DLR, including four transfer flights between Oberpfaffenhofen, Germany, and the air base in Keflavík, Iceland. An overview of the flights, wind scene periods and the num- ber of A2D observations is presented in Table 1. Twentyseven flight legs with continuous sampling of wind profiles were conducted with periods ranging from $11 \mathrm{~min}$ to more than $1 \mathrm{~h}$, adding up to almost $15 \mathrm{~h}$ over the whole campaign. From the 14 research flights, 2 flights on 28 September and 15 October 2016 were dedicated to the calibration of the A2D instrument. This procedure represents a key part of the wind retrieval and will be described in this chapter. Here, the focus is put on a ground detection scheme that allows for accurate identification of ground signals and hence reduced systematic errors of the calibration parameters. 


\subsection{Response calibrations}

Spectral response calibration of the A2D is a prerequisite for the wind retrieval, since the relationship between the Doppler frequency shift of the backscattered light, i.e. the wind speed, and the response of the two spectrometers has to be known for the wind retrieval. In particular, proper knowledge of the Rayleigh response for different altitudes is necessary, as the spectral shape of the Rayleigh-Brillouin backscatter signal significantly depends on temperature and pressure of the sampled atmospheric volume (Witschas et al., 2014) and thus varies along the laser beam path.

For deriving the frequency dependency of the Rayleigh and Mie channel spectral response, a frequency scan of the laser transmitter is carried out, thus simulating well-defined Doppler shifts of the radiation backscattered from the atmosphere within the limits of the laser frequency stability. During the calibration, the contribution of (real) wind related to molecular or particular motion along the instruments' LOS has to be eliminated, i.e. the LOS wind speed $v_{\text {LOS }}$ needs to be zero. In practice, this is accomplished by flying curves at a roll angle of the Falcon aircraft of $20^{\circ}$, resulting in approximate nadir pointing of the instrument and hence $v_{\mathrm{LOS}} \approx 0$, while assuming that the vertical wind is negligible. Consequently, regions with expectable non-zero vertical winds, e.g. introduced by gravity waves or convection, are avoided in this procedure. Nadir pointing leads to a circular flight pattern of the aircraft which is preferably located over areas with high surface albedo in the UV spectral region (e.g. over ice), hence enabling strong ground return intensities and, in turn, high SNR. In the course of the calibration procedure, which takes about $24 \mathrm{~min}$, highest attention has to be paid to the minimization of all unknown contributions to the Rayleigh and Mie response such as biases resulting from inaccurate co-alignment of the transmit and receive path, temperature variations of the spectrometers or frequency fluctuations of the laser transmitter.

During NAWDEX, six response calibrations have been carried out over Iceland, four over the Vatnajökull glacier and two over ice-free land in the north of the island. During each calibration, the laser frequency was tuned in steps of $26 \mathrm{MHz}$ (corresponding to $4.5 \mathrm{~m} \mathrm{~s}^{-1}$ ) over a $1.4 \mathrm{GHz}$ interval $\left( \pm 125 \mathrm{~m} \mathrm{~s}^{-1}\right)$ and the Rayleigh and Mie responses were determined after averaging over 700 pulses (1 observation) per frequency step. While the Rayleigh response is given by the intensity contrast function of filters $\mathrm{A}$ and $\mathrm{B}$ according to Eq. (1), the Mie response is described by the centroid position of the Fizeau fringe according to Eq. (2). Polynomial fitting is then performed for each individual range gate to derive polynomial coefficients that are later fed into the wind retrieval algorithm (Marksteiner, 2013). Here, a fifth-order polynomial was empirically chosen for fitting the Rayleigh response curves, whereas a linear fit is applied for the Mie response function:

$$
\begin{aligned}
& \Psi_{\text {Ray }}(f)=\sum_{i=0}^{5} c_{i} f^{i}, \\
& \Psi_{\text {Mie }}(f)=C_{0}+C_{1} f .
\end{aligned}
$$

The determined polynomial coefficients for each range gate are then used for the calculation of the Doppler frequency shift from the Rayleigh and Mie responses obtained for each wind observation. Since both the range gate setting and the flight altitude generally differ between the calibration flight and the actual wind scene, a linear interpolation is performed between the coefficients deduced from the calibration in order to obtain the response function for the respective bin altitudes of the wind observation.

For the satellite instrument, the atmospheric Rayleigh response function is derived after adding the return signals obtained from a number of range gates in the upper troposphere (e.g. between 6 and $16 \mathrm{~km}$ ) in order to increase the SNR. The selection of the appropriate range for averaging is performed during on-ground processing and the information for each single range gate is still included in the downlinked raw data. In the satellite wind retrieval for the L2B product, a Rayleigh-Brillouin line shape model is used in combination with atmospheric temperature and pressure profiles from a NWP model (e.g. from ECWMF) to account for the altitudedependence of the Rayleigh response over the entire vertical measurement range from ground to the lower stratosphere (Dabas et al., 2008; Tan et al., 2016).

Unlike for molecular scattering, the backscattering of the laser radiation from aerosols, cloud particles or hard targets does not induce a significant spectral broadening, so that the altitude-dependent variations in temperature and pressure have a negligible impact on the Mie response. Therefore, in contrast to the Rayleigh response calibration, the Mie response function determined for the ground return is sufficient for the wind retrieval and used for all the atmospheric range gates. Due to this fact, precise determination of the coefficients $\left\{C_{0}, C_{1}\right\}$ for the ground is of utmost importance for an accurate Mie wind retrieval. A detailed study on A2D response calibrations and the various influencing factors that affect their quality will be provided in a forthcoming publication. Based on a set of criteria which have been defined over the last years, out of the six available from 2016 one particular calibration, i.e. set of response coefficients $\left\{c_{i}\right\}(i=1$, $\ldots, 5)$ and $\left\{C_{0}, C_{1}\right\}$, was determined as the baseline for the subsequent Rayleigh and Mie wind retrieval.

\subsection{Refined ground detection scheme}

Precise identification of the ground return signals is crucial for exploiting the information included therein. Systematic wind errors which can be caused by changes in the alignment of the transmit-receive path or inaccuracies in the aircraft attitude data can be reduced by applying ZWC. Regarding the aircraft speed of the Falcon, the specification of the 
(a)

(b)

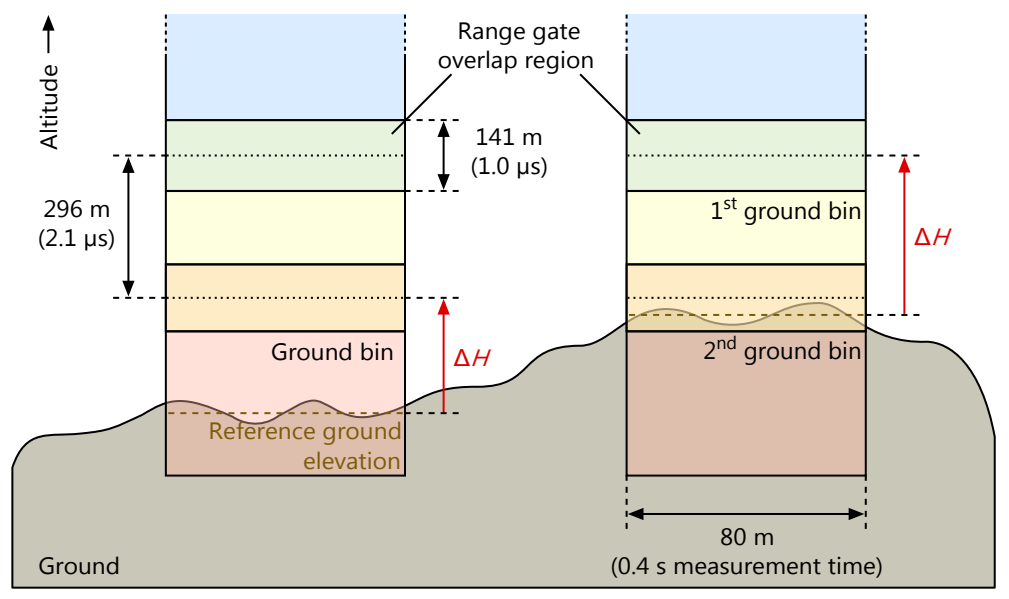

Figure 3. Detection of ground signals with the A2D wind lidar. The sketch shows the vertical position of three neighbouring range gates (blue, yellow and red boxes) with respect to the ground. The ground return signals are either contained in only one range bin (a) or distributed over two range bins due to the range gate overlap (here shown for the Mie channel as green and orange areas) as well as varying elevation of the ground surface within one measurement (b). $\Delta H$ denotes the atmospheric contribution to the signal obtained from the ground bin(s). The given heights of 296 and $141 \mathrm{~m}$ are related to the A2D off-nadir angle of $20^{\circ}$.

incorporated GPS receiver assures an accuracy of better than $0.1 \mathrm{~m} \mathrm{~s}^{-1}$ (Weissmann et al., 2005). Due to the coarse vertical resolution (hundreds of metres) of the $\mathrm{A} 2 \mathrm{D}$ and $\mathrm{AL}$ ADIN, ZWC based on ground return signals is rather challenging, as the ground bin is very likely to be contaminated by atmospheric signals. For the Mie channel, strong aerosol backscatter close to the ground can influence the ground speed measurement, while the SNR of the ground measurement for the Rayleigh channel is diminished by the broad bandwidth molecular return collected from near the ground surface. Moreover, both channels are potentially affected by surface winds, which introduce systematic errors in the measurement of the ground speed or sea surface with non-zero ground speed ( $\mathrm{Li}$ et al., 2010). This situation is aggravated by the fact that the ground signals can be distributed over multiple range bins. First, this is due to the charge transfer process of the ACCD, which leads to a temporal overlap in the acquisition of two subsequent range gates of about $1 \mu \mathrm{s}$. Laser timing fluctuations in combination with charge transfer inefficiency during the readout of the ACCD, especially occurring at high signal intensities, can cause a signal spread over even more than two range gates within a measurement and observation. Second, varying ground elevations during the duration of one measurement $(0.4 \mathrm{~s}, 20$ pulses at $50 \mathrm{~Hz}$ repetition rate) and laser pointing fluctuations can lead to the detection of ground signals in multiple range gates, taking into account that the laser pulses cover a distance of $80 \mathrm{~m}$ along track on the ground at an aircraft speed of $200 \mathrm{~m} \mathrm{~s}^{-1}$. Figure 3 illustrates this circumstance for two cases; one with ground signals completely contained in one range gate (a) and another with ground signals distributed over two range gates (b). The height difference between a reference ground elevation during one measurement and the upper bin border of the highest (or first) range gate that contains ground signals is denoted by $\Delta H$ and represents a measure of the atmospheric contribution to the ground signal detected by the A2D. The reference ground elevation per measurement is derived from the DEM ACE2, providing elevation data at a resolution of $9 \operatorname{arcsec}(300 \mathrm{~m} \times 300 \mathrm{~m}$ at the Equator) (Berry et al., 2010).

In previous A2D studies, ground detection for the calibration mode was based on an analysis of the curtain plot depicting the Rayleigh and Mie signal intensities after range correction and normalization to the integration time of each range gate (see Fig. 4a and b). Here, high signal intensities related to strong ground return become visible as white bins, as the intensity exceeds the maximum of the respective colour scale. Ground range gates were then specified per flight leg and the corresponding signal intensities in the identified range gates were summed up (Marksteiner et al., 2013). For the example shown in Fig. 4, range gates 21 to 23 would be subjectively selected as ground range gates in the old scheme (by visual inspection by an experienced data analyst), since most of the white bins are found therein. This approach leads to an underestimation of the actual ground signal which might also be contained in adjacent range gates as well as to an additional summation of atmospheric signal causing error-prone ground data, especially for varying terrain during the flight leg. The imperfect differentiation between atmospheric and ground return signals thus introduces systematic errors in the ground response functions of both detection channels. Concerning the Mie channel, this affects the entire wind profile, as the ground response is used for the wind retrieval in all atmospheric range gates as men- 

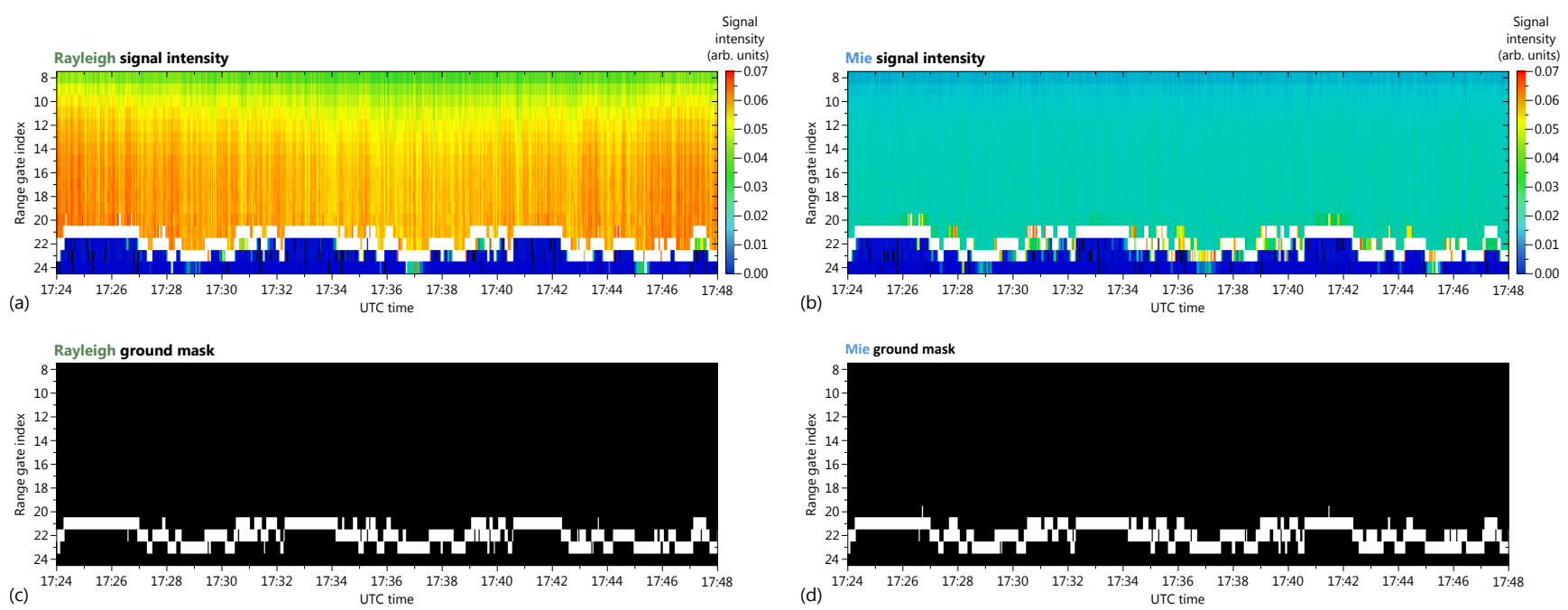

Figure 4. Ground detection during the response calibration performed over Iceland on 15 October 2016 between 17:24 and 17:48 UTC. (a) Signal intensities measured with the A2D Rayleigh channel versus time and the range gates 8 to 24 on measurement level. (b) Mie signal intensity including Rayleigh background on measurement level. The intensities are range-corrected and scaled to the integration time of the respective range gates. Range gates 8 to 19 have a length of $592 \mathrm{~m}$, while range gates 20 to 24 have a length of $296 \mathrm{~m}$. Bins with signal intensities exceeding the maximum of the respective colour scale are printed in white. The Rayleigh and Mie ground masks resulting from the developed ground detection scheme are depicted in panels (c) and (d), respectively. White bins are identified as ground bins and thus considered for the determination of the ground response function.

tioned above. The old ground detection scheme was acceptable in previous airborne campaigns where the response calibrations were performed over flat terrain, e.g. sea ice, so that ground signals were almost completely contained in only one range gate. However, since complex terrain scenes were encountered in the response calibrations during NAWDEX, the ground detection scheme was refined as explained in the following.

In order to derive more accurate ground speeds, a trade-off has to be found between summing up as much ground signal as possible and minimizing the atmospheric portion in the ground bins. For this purpose, a ground detection algorithm on measurement level was developed (Weiler, 2017). Similar to the wind retrieval algorithm employed for Aeolus (Reitebuch et al., 2017, 2018), it is based on a signal-gradient approach to estimate ground bin candidates within a predefined range around the ground level which is given by the DEM. In a range of \pm 3 bins around the expected ground level according to the DEM, the signal gradients of two adjacent bins are calculated for each measurement and per range gate $i$ :

$$
\frac{\Delta I_{i}}{\Delta R_{i}}=\frac{I_{i+1}-I_{i}}{R_{i+1}-R_{i}} .
$$

Here, $I$ denotes integrated signal intensity per measurement, while $R$ is the range from the instrument to the bin centre which can be calculated from the respective range gate integration time. In a next step, gradient thresholds are introduced to identify the uppermost and lowermost ground bin. For the analysed flights, thresholds of $T_{\mathrm{GR}, \text { high }}=0.015 \mathrm{arb}$. units $\mathrm{km}^{-1}$ and
$T_{\mathrm{GR}, \text { low }}=-0.015$ arb. units $\mathrm{km}^{-1}$ (arbitrary units is abbreviated arb. units) have been empirically found to yield consistent results for both the Rayleigh and Mie channel. In order to avoid large atmospheric contribution to the ground signal, another threshold $T_{\mathrm{GR} ; \mathrm{DEM}+1}$ has been implemented which analyses the signal level of the range gate just above the DEM bin covering the reference ground elevation. If the intensity in this bin does not make up more than five percent of the total summed ground signal, it is not considered for the ground signal summation. Careful analysis has shown that ground intensities falling below that threshold have negligible influence on the accuracy of ground response calibration curves or ground wind speeds and thus can be omitted for the ground signal summation (Weiler, 2017). Using this approach, $\Delta H$ and hence the atmospheric portion of the ground signal can be significantly diminished. The ground detection method has been employed for the analysis of the Mie and Rayleigh response calibration data obtained in the NAWDEX campaign and formed the basis for the ZWC applied for the wind scenes on 4 October 2016 discussed in Sect. 4.2. Moreover, the comparison between refined ground detection and the previous scheme allows for the characterization of the influence of the atmospheric contamination of the ground calibration parameters.

The largest influence of the refined scheme on the calibration parameters compared to the former approach was obtained for the sixth response calibration procedure performed during NAWDEX on 15 October 2016 between 17:24 and 17:48 UTC. The Rayleigh and Mie signal intensities measured during the calibration are shown in Fig. $4 a$ and b, re- 
spectively. The calibration flight was carried out in the region around $65.5^{\circ} \mathrm{N}$ and $17.8^{\circ} \mathrm{W}$, which is characterized by a mountainous and ice-free terrain with ground elevations ranging from about 200 to $1200 \mathrm{~m}$. Consequently, ground signals were detected in four different range gates (20 to 23) during the calibration procedure, as the Falcon aircraft flew circular patterns over this region. While the ground response calibration based on the old ground detection method would have summed up all the signals contained in these four range gates for each observation, i.e. frequency step of the calibration, the refined method only considers those bins per measurement that fulfil the threshold conditions as explained above. The corresponding Rayleigh and Mie ground masks illustrating the range bins that were identified as ground bins for each measurement are depicted in Fig. $4 \mathrm{c}$ and d. Due to the different sensitivities of the two receiver channels, and thus different measured signal intensities, the two masks are not fully identical.

For both channels, the atmospheric contribution is drastically reduced resulting in more accurate response values. While the mean value of $\Delta H$ over all measurements of calibration 6 is 454 and $505 \mathrm{~m}$ for the Rayleigh and Mie channel when the old ground detection technique is applied, it is only 207 and $249 \mathrm{~m}$ for the new method, respectively. An overview of the atmospheric contributions (mean $\Delta H$ ) for all the six Rayleigh and Mie response calibrations (RRC and MRC) using the two different ground detection schemes is given in Tables 2 and 3. The tables also summarize the zeroand first-order polynomial coefficients $\left\{c_{0}, c_{1}\right\}$ and $\left\{C_{0}, C_{1}\right\}$ (referred to as intercept and slope) obtained from fitting of the response curves according to Eqs. (3a) and (3b). The second- and higher-order coefficients $\left\{c_{i}\right\}(i=2,3,4,5)$ of the Rayleigh response function are not given. Since calibration 1 was carried out using a different setting of the co-alignment loop reference position $\left(\mathrm{CoG}_{X} / \mathrm{CoG}_{Y}\right)$ (see Sect. 2.1) affecting the incidence angle of the backscattered signals on the Rayleigh and Mie spectrometer, the resulting calibration parameters were disregarded in the statistical calculations leading to the values provided in Tables 2 and 3 .

In general, larger deviations in the slope and intercept values between the two methods are present for the Rayleigh channel. This can be explained by the fact that the broadband Rayleigh channel is more sensitive to the broadband atmospheric molecular background signal than the narrowband Mie channel where the broadband atmospheric contribution leads to a nearly constant intensity offset to the narrowband ground signals. The impact on the Rayleigh channel is especially large in cases of low-albedo surfaces where the atmospheric contribution to the weaker ground signals is more pronounced. As a result, large discrepancies between the calibration parameters obtained with the old and new method are observed for the two last calibrations that were performed over ice-free land with low albedo in the UV. In particular, the intercept values derived for the RRC 6 discussed before differ by as much as $1.24 \times 10^{-2}$. Using a typical Rayleigh response slope value of $4.6 \times 10^{-4} \mathrm{MHz}^{-1}$ (Table 2) and the conversion between Doppler frequency shift and LOS wind speed $\left(1 \mathrm{~m} \mathrm{~s}^{-1} \widehat{=} 5.63 \mathrm{MHz}\right)$ introduced in Sect. 2.2 , this difference in intercept translates to a wind speed difference of $4.8 \mathrm{~m} \mathrm{~s}^{-1}$. That means that ground speed values determined from RRC 6 using either the old or the new ground detection method would differ by that value. With a view to ZWC, the large discrepancy in the ground speed values underlines the relevance of proper ground detection for the wind retrieval, as the ground speeds are used as zero reference for the derived wind speeds. Likewise, using the refined ground detection method for the analysis of MRC 6 results in a change in the Mie intercept values by $11.7 \times 10^{-3}$ pixel which corresponds to a wind speed difference of $0.2 \mathrm{~m} \mathrm{~s}^{-1}$, considering a typical Mie response slope of about $100 \mathrm{MHz}_{\text {pixel }}{ }^{-1}$ (Table 3).

Another aspect that becomes obvious from Tables 2 and 3 is that the spread of intercept values between the different Rayleigh response calibrations is reduced when applying the new ground detection method. The standard deviation over the five RRCs 2 to 6 is $1.02 \times 10^{-2}$, whereas it is $0.68 \times 10^{-2}$ for the new method. Hence, depending on the calibration used for the wind retrieval, the Rayleigh ground wind speed varies by $3.9 \mathrm{~m} \mathrm{~s}^{-1}$ if the old technique is applied. This value is reduced by more than $30 \%$ to $2.6 \mathrm{~m} \mathrm{~s}^{-1}$ with the new scheme, which is still unsatisfactorily large regarding the consistency of Rayleigh response calibrations. For the Mie channel, no change in the spread of the calibration parameters is evident. Nevertheless, the new ground detection approach provides a considerable improvement in the accuracy of the ground calibration parameters and, in turn, of the derived ground wind speeds. With a view to the Aeolus mission, it can be concluded that calibrations should be performed over surfaces with high albedo, like ice surfaces, in order to minimize the impact of the atmospheric contamination. Furthermore, the quantity $\Delta H$ could be considered as a quality parameter for evaluating the quality of response calibrations or even to correct calibrations for the atmospheric contribution.

\section{Wind retrieval and assessment of accuracy}

This chapter discusses the wind results from two selected flights performed on 27 September and 4 October 2016 to demonstrate the Rayleigh and Mie wind retrieval algorithms as well as their subsequent validation by statistical comparison with the data obtained with DLR's coherent reference wind lidar system. 
Table 2. Rayleigh response calibration parameters obtained from the six calibrations performed on 28 September and on 15 October 2016. The zero- and first-order fitting parameters $c_{0}$ and $c_{1}$ were derived involving the old ground and new ground (GR) detection method (see text). The atmospheric contribution $\Delta H$ (see Fig. 3) has been averaged over the respective calibration period. Calibration 1 was performed using a different alignment of the lidar system and is thus excluded from the statistical calculations.

\begin{tabular}{|c|c|c|c|c|c|c|c|c|}
\hline \multirow[t]{2}{*}{ RRC no. } & \multirow[t]{2}{*}{ Date } & \multirow[t]{2}{*}{ Surface } & \multicolumn{2}{|c|}{ Mean $\Delta H(\mathrm{~m})$} & \multicolumn{2}{|c|}{ Slope $\left(c_{1}\right)\left(10^{-4} \mathrm{MHz}^{-1}\right)$} & \multicolumn{2}{|c|}{ Intercept $\left(c_{0}\right)\left(10^{-2}\right)$} \\
\hline & & & $\begin{array}{l}\text { Old GR } \\
\text { detection }\end{array}$ & $\begin{array}{l}\text { New GR } \\
\text { detection }\end{array}$ & $\begin{array}{l}\text { Old GR } \\
\text { detection }\end{array}$ & $\begin{array}{l}\text { New GR } \\
\text { detection }\end{array}$ & $\begin{array}{l}\text { Old GR } \\
\text { detection }\end{array}$ & $\begin{array}{l}\text { New GR } \\
\text { detection }\end{array}$ \\
\hline 1 & 28/09/2016 & Ice & 480 & 308 & 4.58 & 4.43 & 1.15 & 1.39 \\
\hline 2 & 28/09/2016 & Ice & 753 & 519 & 4.46 & 4.42 & 1.62 & 1.73 \\
\hline 3 & 28/09/2016 & Ice & 734 & 522 & 4.48 & 4.44 & 1.60 & 1.70 \\
\hline 4 & $15 / 10 / 2016$ & Ice & 606 & 546 & 4.64 & 4.63 & 0.32 & 0.36 \\
\hline 5 & $15 / 10 / 2016$ & Ice-free land & 411 & 249 & 4.92 & 4.78 & -0.32 & 0.42 \\
\hline 6 & $15 / 10 / 2016$ & Ice-free land & 454 & 207 & 4.82 & 4.69 & -0.47 & 0.77 \\
\hline Mean & & & 592 & 409 & 4.66 & 4.59 & 0.55 & 1.00 \\
\hline Standard deviation & & & 157 & 166 & 0.20 & 0.16 & 1.02 & 0.68 \\
\hline
\end{tabular}

Table 3. Mie response calibration parameters obtained from the six calibrations performed on 28 September and on 15 October 2016 . The zero- and first-order fitting parameters $C_{0}$ and $C_{1}$ were derived involving the old ground and new ground (GR) detection method (see text). The atmospheric contribution $\Delta H$ (see Fig. 3) has been averaged over the respective calibration period. Calibration 1 was performed using a different alignment of the lidar system and is thus excluded from the statistical calculations.

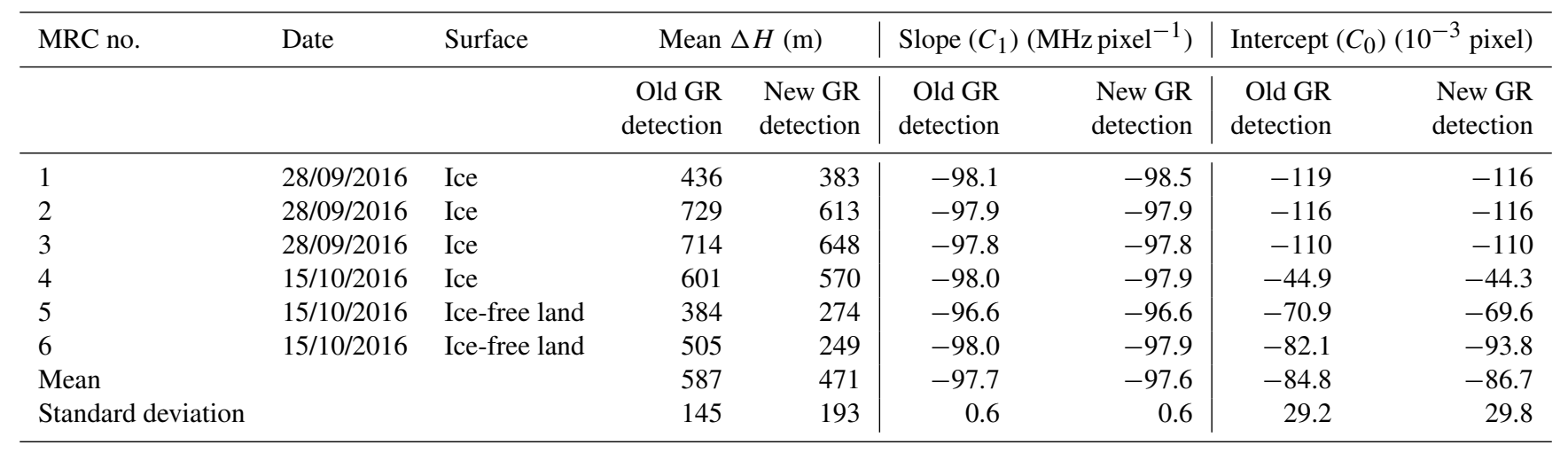

\subsection{Jet stream wind observations over the North Atlantic on 27 September 2016}

While the instrument response calibrations were performed during two dedicated flights over Iceland, the other 12 research flights within the NAWDEX campaign were devoted to wind observations over the North Atlantic region. Here, sampling of the jet stream was of particular interest with regards to both the pre-launch activities of Aeolus and the scientific objectives related to atmospheric dynamics. The observation of high horizontal wind speeds and large wind gradients occurring in relation to the jet provided an extensive characterization of the instrument over a large operating range and accurate wind profiles for the NAWDEX science objectives. In the context of the fourth NAWDEX intensive observation period, the goal of the flight carried out on 27 September 2016 was to observe very high jet stream wind speeds related to the former tropical cyclone Karl. As Karl moved towards the mid-latitudes, it merged with an initially weak downstream cyclone and strongly intensified. Later, at the time of the flight, the already weakened cyclone was located between Iceland and Scotland and the zonally oriented jet stream extended towards Scotland with horizontal wind speeds exceeding $80 \mathrm{~m} \mathrm{~s}^{-1}$ at altitudes of 9 to $10 \mathrm{~km}$ (see Fig. 5 and for a detailed description of the meteorological situation refer to Schäfler et al., 2018). To observe the high wind speeds, the Falcon aircraft flew towards the Faroe Islands and the Outer Hebrides right into the centre of the jet stream at a flight altitude of $11.5 \mathrm{~km}$ before returning to the air base in Keflavík. The satellite image taken from the Moderate Resolution Imaging Spectroradiometer (MODIS) instrument aboard NASA's Terra satellite (MODIS, 2017a), shown in Fig. 5a, depicts increased cloud coverage along the flight track crossing the cyclone. From the total flight duration of $3 \mathrm{~h}$ and $56 \mathrm{~min}$ (09:28 to 13:24 UTC), wind observations were conducted in the period between 10:28 and 12:36 UTC, split into two scenes of about $1 \mathrm{~h}$ each. 

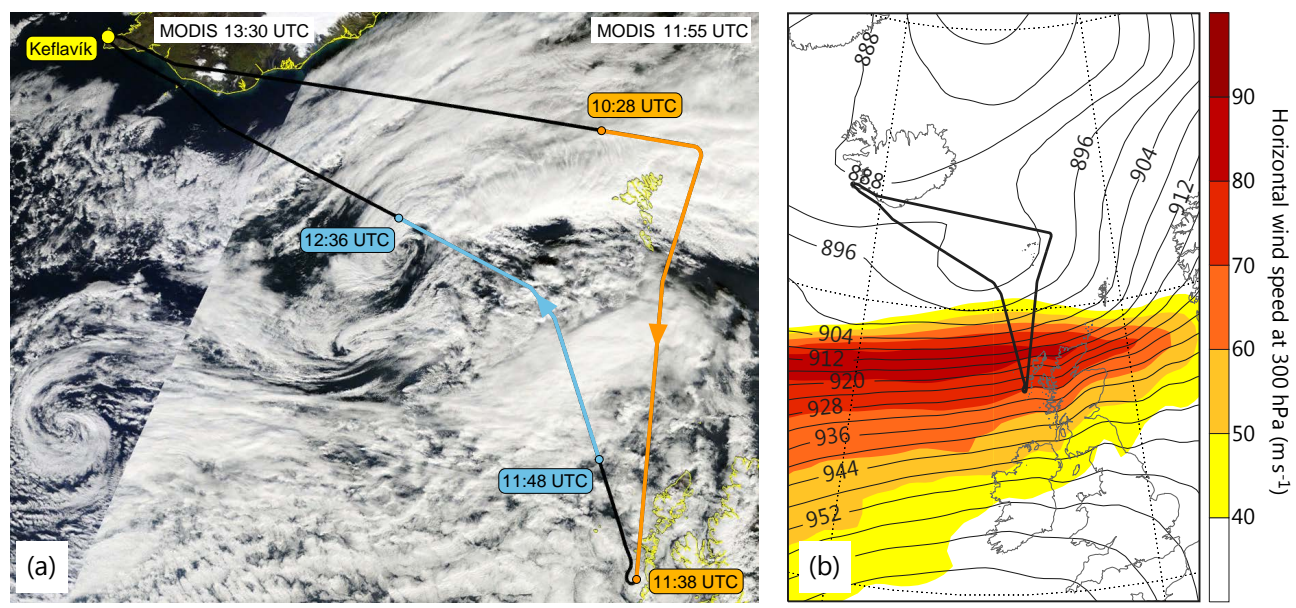

Figure 5. (a) Flight track of the Falcon aircraft (black line) during the research flight conducted on 27 September 2016. The wind scenes performed from 10:28 to 11:38 and from 11:48 to 12:36 UTC are indicated in orange and blue. The background picture is composed of a map provided by Google Earth and satellite images from Terra MODIS (VIS channel) taken at 11:55 (right part) and 13:30 UTC (left part) (MODIS, 2017a). (b) Geopotential height (black isolines, in dekametres) and horizontal wind speed (colour shading) at $300 \mathrm{hPa}$ on 27 September 2016, 12:00 UTC, from ECMWF model analysis together with the flight track of the Falcon 20 aircraft.

\subsubsection{Rayleigh background subtraction and quality control}

In the period from 11:41 to 11:47 UTC the A2D was operated at a different mode which aimed at the detection of the Rayleigh background signal on the Mie channel. Proper quantification of the broadband molecular return signal transmitted through the Fizeau interferometer is important for avoiding systematic errors in the determination of the fringe centroid position and, in turn, in the Mie winds. Therefore, the laser frequency was tuned away by $1.1 \mathrm{GHz}$ from the Rayleigh filter cross point and the Mie spectrometer centre position which define the nominal set frequency during the wind scenes (see Fig. 2a). In this way, the laser frequency of the emitted pulses was outside of the useful spectral range of the Mie spectrometer, so that the fringe was not imaged onto the Mie ACCD and only the broadband Rayleigh signal was detected on the Mie channel. The range-dependent intensity levels per pixel were subsequently subtracted from the measured raw Mie signal. In the near-field range gates, the measured intensity distribution over the pixel array measured by the Mie and Rayleigh ACCDs is substantially impacted by the central obscuration of the telescope pupil by the secondary mirror and its supporting spider. Furthermore, the data obtained from the near-field region is affected by the incomplete overlap of the transmitted laser beam with the telescope FOV as well as by the attenuation of the signals by the EOM (Paffrath et al., 2009). Therefore, the atmospheric range gates in the region within $1.5 \mathrm{~km}$ below the aircraft (range gates 5 and 6) were not considered in the wind retrieval.

The Rayleigh as well as the Mie signal intensities after Rayleigh background correction per observation (18s) are shown in Fig. 6a and b, respectively. The raw signals were first corrected for the DCO and the solar background which are collected in two separate range gates. Moreover, a range correction was applied taking into account that the intensity decreases as the inverse square of the distance between the scatterer and the detector. Finally, the integration times set for each range gate were considered for normalizing the signal intensities per bin. Curve flights during the flight section are manifested in altitude variations of the range gate borders, as a change in the roll angle of the aircraft involved a change in the off-nadir angle of the A2D. While the intensity profiles for the Rayleigh channel essentially follow the vertical distribution of the atmospheric molecular density, the Mie intensity profiles display the vertical distribution of atmospheric cloud and aerosol layers along the flight track. High Rayleigh signal intensities above 3.5 arb. units (dark red bins in Fig. 6a) can be attributed to cloud layers at different altitudes along the flight track which also manifest in increased Mie signal intensities (Fig. 6b).

As a preparatory step of the wind retrieval, several quality control (QC) mechanisms were applied to exclude invalid data. The detection of corrupted measurements within one observation involved the screening for DCO outliers, saturated pixels on the ACCDs as well as for failure of the trigger that initiates the detector electronics. The latter causes an untimely ACCD acquisition, and hence an incorrect allocation of the internal reference and atmospheric return signals to their designated range gates. For the actual wind retrieval, the wind speeds for each atmospheric range gate were determined from the respective frequency differences to the internal reference frequency. The frequencies were calculated from the corresponding Rayleigh and Mie response functions (Eqs. 3a and b) derived during the calibration mode. As a re- 

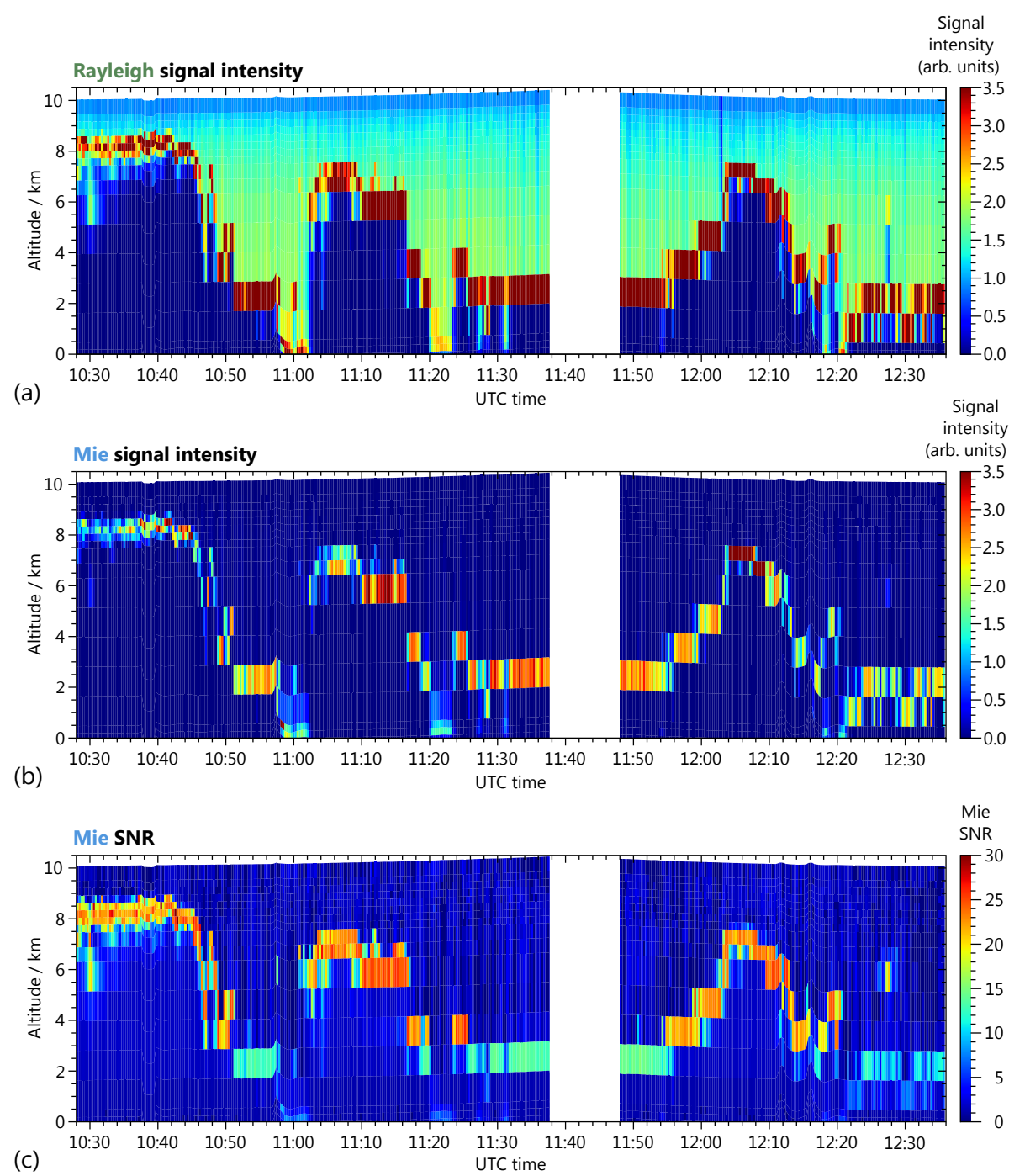

Figure 6. Signal intensities measured for (a) the A2D Rayleigh channel and (b) the A2D Mie channel during the flight on 27 September 2016 between 10:28 and 12:36 UTC. The intensities are range-corrected and scaled to the integration time of the respective range gates. The background and detection chain offset were subtracted. For the Mie channel, the Rayleigh background signal was subtracted as explained in the text. The detection of the Rayleigh background signal was performed between 11:41 and 11:47 UTC, leading to a data gap in this period. (c) Mie SNR calculated according to Eq. (3.29) in Marksteiner (2013). Bins with signal intensities exceeding the maximum of the respective colour scale are printed in dark red.

sult, separate wind profiles for the Rayleigh and Mie channel were obtained. While the Rayleigh profiles only contain valid wind data in range bins in which purely molecular backscattering occurred, the Mie wind profiles are composed of wind data retrieved from areas with sufficient cloud and aerosol content. However, since the retrieval initially produces wind values for all data bins in both channels, additional measures had to be taken to identify and eliminate invalid wind data. The procedures differ between the Rayleigh and Mie profiles and will be outlined in the following sections.

\subsubsection{Rayleigh wind profiles}

The identification of invalid winds retrieved from the Rayleigh channel was based on the detection of bins which were affected by particulate backscatter from clouds or aerosols, since this Mie contamination introduces systematic errors of the measured Rayleigh response (Dabas et al., 2008). Therefore, as introduced in Marksteiner (2013), bins showing range-corrected and integration time-corrected Rayleigh signal intensities that are unusually high for pure molecular backscatter were excluded from further analysis. An intensity threshold of $0.1 \mathrm{arb}$. units per measurement was found to be an appropriate value for identify- 
ing Mie-contaminated bins in the Rayleigh channel. Under clear conditions Rayleigh signal intensities on observation level (summed over 35 measurements) are well below 3.5 arb. units (see Fig. 6a). Due to the attenuation of the laser beam during propagation through the clouds, the wind information obtained from the range gates below clouds is very likely to be also derogated. Consequently, not only the cloud bins themselves are flagged invalid but also all the bins in the range gates below. Additionally, ground bins that were detected by the scheme described in Sect. 3.2 as well as bins containing valid Mie wind data (see next section) were removed from the Rayleigh wind profiles.

Figure 7a shows the processed LOS Rayleigh winds plotted versus time and altitude for the period from 10:28 to 12:36 UTC after removal of invalid bins as described above. During the first section of the flight, the horizontal component of the A2D LOS unit vector was nearly parallel to the horizontal wind vector and pointing against the wind, resulting in high positive LOS wind speeds (yellow/orange colours), whereas negative wind speeds of comparable magnitude were measured during the second flight leg when the LOS unit vector was oriented along the direction of the wind, i.e. the wind was pointing away from the instrument (blue colours). The data gap in between is due to the curve flight near the Outer Hebrides as well as the procedure required for Rayleigh background subtraction mentioned above. The figure also illustrates the range-dependent vertical resolution of the instrument. For the presented flight section, the integration time of the ACCD was set to $2.1 \mu$ s in the range gates 8 to $14(9.4$ to $7.7 \mathrm{~km})$ and those close to the ground $(22,23)$; $4.2 \mu$ s in the range gates 7,15 and $16(6.1 \mathrm{~km})$; and $8.4 \mu \mathrm{s}$ in all the remaining atmospheric range gates, corresponding to a height resolution of 296, 592 and $1184 \mathrm{~m}$, respectively. This range gate setting was the same for the Rayleigh and Mie channel and chosen in order to resolve the wind structure within the core of the jet stream. In this region, broad coverage of Rayleigh winds was obtained, while mid-level clouds prevented the acquisition of valid Rayleigh wind data on the edges of the jet below their tops between 4 and $7 \mathrm{~km}$ height. In addition, high-level clouds at the beginning of the shown flight section limited the extension of the Rayleigh wind profiles to the range from 9 to $10 \mathrm{~km}$.

One characteristic of the Rayleigh channel is the fluctuating wind error from profile to profile, which becomes visible as a vertical texture in the two-dimensional wind curtain. The underlying reason is the high sensitivity of the Rayleigh response to variations in the incidence angle on the FPI. Despite the active transmit-receive co-alignment loop, residual angular variations on the order of a few $\mu \mathrm{rad}$, which are due to atmospheric turbulence and the effect of strong cloud backscatter onto the co-alignment algorithm, cause fluctuations in the derived wind speeds of several metres per second. The introduced error is thus correlated among the atmospheric range gates, and the mean error varies from observation to observation, resulting in a vertical pattern in the Rayleigh wind curtain. Measures are being examined to reduce this fluctuation by a refined co-alignment feedback loop, for instance, by employing a UV camera with higher resolution in combination with an improved algorithm for determining the centre of gravity of the backscattered laser radiation.

\subsubsection{Mie wind profiles}

The validity of the Mie wind determined for each bin is related to the cloud and aerosol loading in the respective range gate, and thus the signal intensity detected on the Mie ACCD. For the proper identification of bins with sufficient particulate backscatter return signal, the so-called Mie SNR was defined as the quotient between the signal of the pixel with the highest intensity, i.e. the fringe centre, and the mean over the pixels that lie outside the fringe (Marksteiner, 2013). The Mie SNR calculated for the studied measurement scene is depicted in Fig. 6c. Based on the SNR profile, a threshold value was set which allowed sorting out corrupt wind measurement bins. For the analysed wind scene, a Mie SNR threshold of 5.0 was empirically chosen in order to remove those bins where low particle backscatter coefficients prevented the correct determination of the Mie fringe centroid position and thus the acquisition of accurate wind speeds.

The resulting two-dimensional Mie wind curtain is shown in Fig. 7b. As opposed to the Rayleigh channel, the Mie data coverage is rather sparse owing to the little cloud cover and low aerosol load during the flight. Wind data are mainly obtained from the cloudy regions mentioned above, thus complementing the wind information gained with the Rayleigh channel. The combination of the Rayleigh and Mie wind data, displayed in a composite curtain in Fig. 7c, illustrates the complementarity of the two detection channels which enables the acquisition of wind speeds under various atmospheric conditions, hence ensuring broad data coverage for the entire scene. In the case that valid winds are obtained for both channels, the Mie wind is preferred due to the higher accuracy and precision of the Mie channel for the A2D (see next sections). Figure 8a shows the combined Rayleigh and Mie wind curtain along two flight legs in the region of the jet stream. Here, the horizontal LOS (HLOS) wind speed is illustrated, which was calculated from the measured LOS wind speeds and the off-nadir angle of the instrument $\left(\approx 20^{\circ}\right)$ per observation. Strong vertical wind gradients exceeding $10 \mathrm{~m} \mathrm{~s}^{-1} \mathrm{~km}^{-1}$ at about $5 \mathrm{~km}$ altitude become apparent in Fig. 8b, which depicts the HLOS wind profiles from two selected observations starting at 11:28:21 and 11:54:09 UTC. The vertical position of the data points corresponds to the altitude at the centre of the respective range bin. HLOS wind speeds above $80 \mathrm{~m} \mathrm{~s}^{-1}$ were measured in the centre of the sampled jet stream, which is in agreement with the modelled wind field shown in Fig. 5, considering the difference in the angle between the HLOS unit vector of the A2D and the horizontal wind vector. 


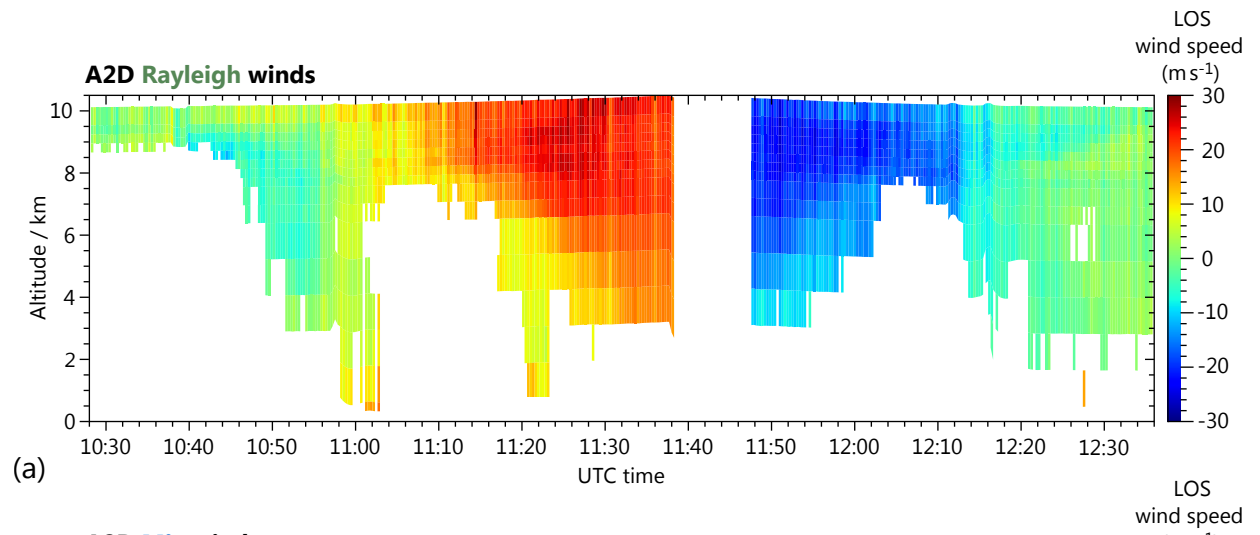

(b)
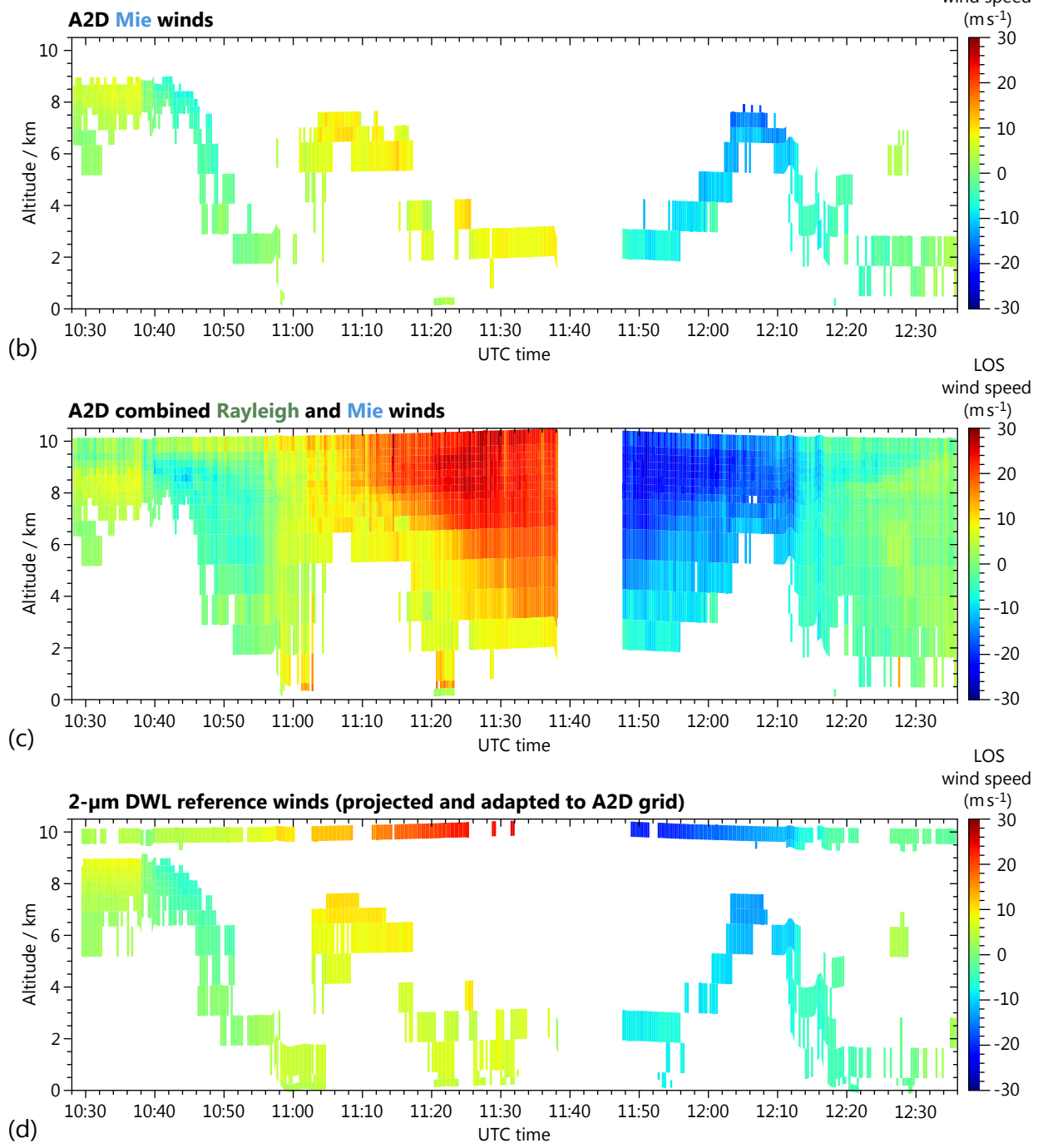

Figure 7. LOS wind profiles (positive towards the instrument) measured during the flight on 27 September 2016 between 10:28 and 12:36 UTC using (a) the A2D Rayleigh channel and (b) the A2D Mie channel. The combination of both channels is depicted in panel (c), while panel (d) shows the corresponding wind curtain obtained with the coherent $2 \mu \mathrm{m}$ reference wind lidar. For better comparison, the $2 \mu \mathrm{m}$ wind data were adapted to the measurement grid of the A2D. White colour represents missing or invalid data due to low signal, e.g. in case of low aerosol loads or below dense clouds. The data gap between 11:38 and 11:48 UTC is due to an interruption of the wind measurement during a curve flight and a different operation mode of the A2D instrument aiming at the detection of the Rayleigh background signals on the Mie channel. 

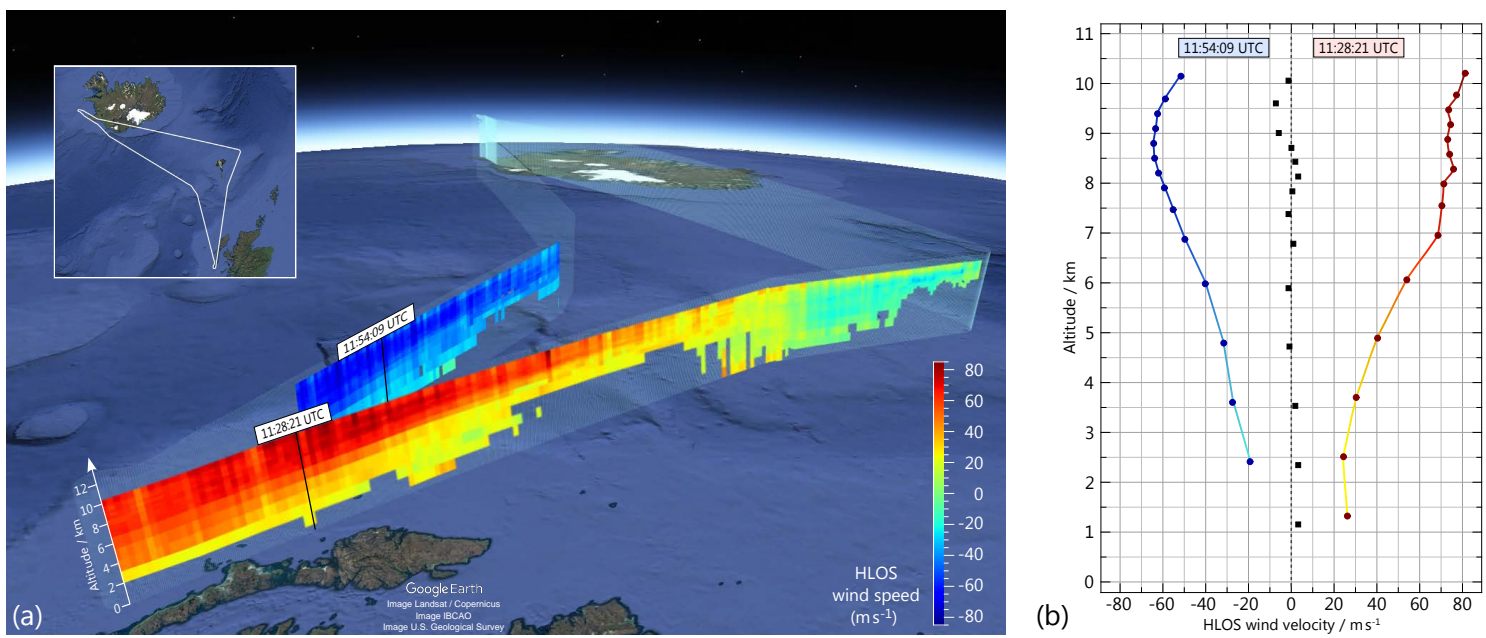

Figure 8. Flight track of the Falcon 20 aircraft for the research flight on 27 September 2016 together with the overlaid A2D HLOS wind profiles measured between 10:40 and 11:38 UTC (foreground) as well as between 11:48 and 12:12 UTC (background), whilst crossing the North Atlantic jet stream (background image: (C2017 Google). (b) Wind profiles from two selected observations starting at 11:28:21 and 11:54:09 UTC. The black squares indicate the mean bias per range gate based on the comparison with wind data from the $2 \mu \mathrm{m}$ coherent wind lidar (see text).

\subsubsection{Coherent wind lidar as reference system}

Validation of the A2D instrument performance and wind retrieval algorithms was performed by comparing the resulting wind profiles to those obtained with DLR's well-established coherent wind lidar system emitting at $2 \mu \mathrm{m}$ wavelength and $500 \mathrm{~Hz}$ repetition rate, which was operating in parallel on board the Falcon aircraft, providing accuracy of the horizontal wind speed of better than $0.1 \mathrm{~m} \mathrm{~s}^{-1}$ and precision of better than $1 \mathrm{~m} \mathrm{~s}^{-1}$ (Weissmann et al., 2005; Chouza et al., 2016b). In contrast to the A2D, the determination of the Doppler shift by the $2 \mu \mathrm{m}$ lidar system relies on heterodyne detection using the instruments' seed laser as local oscillator (Witschas et al., 2017) and thus does not rely on any calibration procedures. Moreover, the coherent wind lidar incorporates a scanner which allows retrieving the three-dimensional horizontal wind vector from a number of LOS wind measurements with a vertical resolution of $100 \mathrm{~m}$. For this purpose, the instrument performs conical scans at an off-nadir angle of $20^{\circ}$, while the information from 21 azimuthal positions is used for the wind vector retrieval. On each azimuthal position the signal from 500 laser pulses (1 s) is averaged to obtain one LOS profile. The time for positioning the laser at its scan starting position is around $21 \mathrm{~s}$, resulting in a total time of $42 \mathrm{~s}$ for one observation of the $2 \mu \mathrm{m}$ wind lidar, whereas one A2D observation takes $18 \mathrm{~s}$ as outlined above.

For adequate comparison of the wind profiles measured with the $2 \mu \mathrm{m}$ and the A2D wind lidar, the three-dimensional wind vectors had to be projected onto the A2D LOS axis. This was carried out for each $2 \mu \mathrm{m}$ observation by calculating the scalar product of the measured wind vector and the mean A2D LOS unit vector under consideration of the aircraft at- titude during the respective observation period. Furthermore, the different spatial and temporal resolutions of the two wind lidar instruments necessitated an adaptation of the $2 \mu \mathrm{m}$ measurement grid to that of the A2D. This was accomplished by a weighted aerial interpolation algorithm (Marksteiner et al., 2011). Here, one considers the whole two-dimensional A2D wind curtain overlaid by the $2 \mu \mathrm{m}$ grid. Hence, a single A2D bin can be covered by multiple $2 \mu \mathrm{m}$ bins both horizontally and vertically. The overlapping regions form a new composite $2 \mu \mathrm{m}$ bin. The contributions of the single $2 \mu \mathrm{m}$ winds to the wind value allocated to the composite bin are weighted by the overlap of the respective $2 \mu \mathrm{m}$ bins with the regarded A2D bin. In this way, the A2D and $2 \mu \mathrm{m}$ wind profiles can be compared on a bin-to-bin basis.

In order to reduce the risk of large discrepancies between the interpolated $2 \mu \mathrm{m}$ wind and the compared A2D wind in case of low coverage, a minimum overlap of the compared bins (coverage ratio threshold) has been introduced as a QC parameter. For the considered wind scene, a threshold value of $25 \%$ was found to provide an optimal trade-off between comparability and quantity of the $2 \mu \mathrm{m}$ bins, thus yielding an acceptable number (nearly 1000) of representative composite $2 \mu \mathrm{m}$ bins used for comparison. Increasing the coverage ratio threshold, e.g. to $80 \%$, would have reduced the number of bins to less than 500 without significant change in the parameters resulting from the statistical comparison. Furthermore, proper analysis of the Rayleigh winds with a sufficient number of compared bins $(>300)$ required a threshold of less than $45 \%$.

The projected LOS wind curtain obtained from the $2 \mu \mathrm{m}$ DWL after adaptation to the A2D measurement grid is depicted in Fig. 7 d. Since the $2 \mu \mathrm{m}$ DWL purely relies on par- 
ticulate backscatter, the data coverage is similar to that of the A2D Mie channel, resulting in a large overlap of the two data types. Consequently, the number of bins available for comparison is greater than for the Rayleigh channel. However, the availability of $2 \mu \mathrm{m}$ wind data from the upper region of the jet stream between 9 and $10 \mathrm{~km}$ altitude allows for the comparison of Rayleigh wind data over a broad range of wind speeds.

\subsubsection{Statistical comparison of A2D and $2 \mu \mathrm{m}$ DWL winds}

The statistical comparison of the Rayleigh and Mie winds with the $2 \mu \mathrm{m}$ DWL data from the discussed flight section is visualized in Fig. 9a. Here, the A2D winds are plotted versus the corresponding interpolated $2 \mu \mathrm{m}$ winds, resulting in a cloud of data points that ideally lie on the dashed line representing $v_{\mathrm{A} 2 \mathrm{D}}=v_{2 \mu \mathrm{m}}$. The non-weighted linear fit $v_{\mathrm{A} 2 \mathrm{D}}=A \cdot v_{2 \mu \mathrm{m}}+B$ through the real data provides values for the slope $A$ and intercept $B$ that generally deviate from the ideal result $A=1$ and $B=0$. The statistical values derived from the scatterplot are summarized in Table 4, showing that the fitting parameters for both Rayleigh and Mie channels only slightly deviate from the ideal case $(A \approx 1$, $\left.|B|<0.5 \mathrm{~m} \mathrm{~s}^{-1}\right)$. The standard error of the slope given in the table was calculated according to

$$
\begin{aligned}
s_{A} & =\sqrt{\frac{\frac{1}{n-2} \sum_{i=1}^{n} \varepsilon_{i}^{2}}{\sum_{i=1}^{n}\left(v_{2 \mu \mathrm{m}, i}-\overline{v_{2 \mu \mathrm{m}}}\right)^{2}}}, \text { with } \\
\varepsilon_{i} & =v_{\mathrm{A} 2 \mathrm{D}, i}-\left(A \cdot v_{2 \mu \mathrm{m}, i}+B\right)
\end{aligned}
$$

being the residuals of the linear regression. It should be noted that the parameters derived from the statistical comparison are influenced by the systematic and random errors of both the A2D and the $2 \mu \mathrm{m}$ lidar. However, since the latter provides high accuracy and precision as stated above, the total errors are dominated by the systematic and random error of the A2D.

Aside from the standard deviation, the median absolute deviation (MAD) was determined as an additional parameter for evaluating the random error of the A2D wind speed measurements. It is defined as the median of the absolute variations of the measured wind speeds from the median of the wind speed differences:

$$
\begin{aligned}
\operatorname{MAD} & =\operatorname{median}\left[\mid\left(v_{\mathrm{A} 2 \mathrm{D}, i}-v_{2 \mu \mathrm{m}, i}\right)\right. \\
& \left.-\operatorname{median}\left(v_{\mathrm{A} 2 \mathrm{D}, i}-v_{2 \mu \mathrm{m}, i}\right) \mid\right] .
\end{aligned}
$$

The MAD represents a robust measure of the variability of the measured wind speeds and is more immune to outliers compared to the standard deviation $\sigma$. If the random wind error is normally distributed, the MAD value is related to the standard deviation as $\sigma \approx 1.4826 \cdot \mathrm{MAD}$. The latter quantity is referred to as scaled MAD.
Six bins with wind speed differences $v_{\mathrm{A} 2 \mathrm{D}}-v_{2} \mu \mathrm{m}$ larger than $\pm 10 \mathrm{~m} \mathrm{~s}^{-1}$ were identified as gross errors in the Rayleigh data set and thus removed from the sample. Gross errors are assumed to be uniformly distributed over the wind speed measurement range and add to the Gaussiandistributed random errors. As described in the Mission Requirement Document of the satellite mission (ESA, 2016), the error model for Aeolus also separates between these two different errors and defines a requirement on the probability of gross outliers $(<5 \%)$. In order to identify gross errors in the Aeolus wind results, an estimation of the random error is provided for each observation and used as QC parameter. In addition, NWP centres usually apply a QC (or even variational QC) during the assimilation of the wind products by comparing it with best guess values (background) from the model.

The scatterplot illustrates the good agreement of the A2D and $2 \mu \mathrm{m}$ DWL data over the range of LOS wind speeds from -22 to $+26 \mathrm{~m} \mathrm{~s}^{-1}$. For both detection channels the correlation coefficient is as high as $r=0.97$. Aside from the different wind speed span, the Rayleigh and Mie winds primarily differ with respect to the mean bias $\left(v_{\mathrm{A} 2 \mathrm{D}}-v_{2 \mu \mathrm{m}}\right)$ over all data points representing the accuracy of the instrument. Here, the Mie wind bias almost vanishes $\left(-0.03 \mathrm{~m} \mathrm{~s}^{-1}\right)$, which is due to the fact that the A2D winds are nearly symmetrically distributed about the reference $2 \mu \mathrm{m}$ winds, leading to positive and negative deviations of similar magnitude which compensate for each other.

For the Rayleigh winds, a negative bias of $-0.49 \mathrm{~m} \mathrm{~s}^{-1}$ is obtained, resulting in a mean bias of the combined Rayleigh and Mie data of about $-0.21 \mathrm{~m} \mathrm{~s}^{-1}$. The corresponding HLOS wind speed bias of $-0.61 \mathrm{~m} \mathrm{~s}^{-1}\left(=-0.21 / \sin \left(20^{\circ}\right)\right)$ is considered to be adequate with regards to the Aeolus mission where absolute HLOS mean bias values better than $0.7 \mathrm{~m} \mathrm{~s}^{-1}$ are required. However, it should be noted that the mean bias shows larger values when considered per range gate, as depicted in Fig. 8b. The extreme bias values $>3 \mathrm{~m} \mathrm{~s}^{-1}$ in range gates 8 to 10 lack statistical significance, as they result from a very small number of compared bins due to the scarce data coverage of the $2 \mu \mathrm{m}$ DWL at altitudes between 8.5 and $9.5 \mathrm{~km}$. For the other range gates, the mean bias varies between -0.7 and $0.3 \mathrm{~m} \mathrm{~s}^{-1}$.

Another important statistical parameter for the evaluation of the instrument performance is the standard deviation, which represents the random error and hence the precision of the A2D. Here, the Mie winds show a value of $1.5 \mathrm{~m} \mathrm{~s}^{-1}$ (HLOS: $4.3 \mathrm{~m} \mathrm{~s}^{-1}$ ) which is beyond the requirements of Aeolus. In order to meet the mission goals, the satellite instrument should provide a precision of $1 \mathrm{~m} \mathrm{~s}^{-1}$ in the planetary boundary layer, $2.5 \mathrm{~m} \mathrm{~s}^{-1}$ in the troposphere and 3 to $5 \mathrm{~m} \mathrm{~s}^{-1}$ in the stratosphere (ESA, 2016). The random error can also be approximated from probability density functions (PDFs) illustrating the frequency distribution of the wind speed differences $v_{\mathrm{A} 2 \mathrm{D}}-v_{2 \mu \mathrm{m}}$, i.e. the wind error, for the Rayleigh and Mie channel (see Fig. 9b and c). For the Mie chan- 
Table 4. Results of the statistical comparison between the A2D and the $2 \mu \mathrm{m}$ LOS wind data measured on 27 September 2016 . The statistical comparison has been performed for the Rayleigh and Mie wind profiles (see corresponding scatterplots in Fig. 9) as well as for the combined wind curtain as shown in Fig. 7c.

\begin{tabular}{lrrr}
\hline Statistical parameter & Rayleigh winds & Mie winds & Combined winds \\
\hline Number of compared bins & 381 & 562 & 943 \\
Number of removed bins due to gross error $\left(> \pm 10 \mathrm{~m} \mathrm{~s}^{-1}\right)$ & 6 & 0 & 6 \\
Correlation coefficient $r$ & 0.97 & 0.98 & 0.97 \\
Slope $A$ & $1.002 \pm 0.012$ & $1.004 \pm 0.009$ & $1.002 \pm 0.008$ \\
Intercept $B$ & $-0.49 \mathrm{~m} \mathrm{~s}^{-1}$ & $-0.03 \mathrm{~m} \mathrm{~s}^{-1}$ & $-0.21 \mathrm{~m} \mathrm{~s}^{-1}$ \\
Mean bias & $-0.49 \mathrm{~m} \mathrm{~s}^{-1}$ & $-0.03 \mathrm{~m} \mathrm{~s}^{-1}$ & $-0.21 \mathrm{~m} \mathrm{~s}^{-1}$ \\
Standard deviation & $2.7 \mathrm{~m} \mathrm{~s}^{-1}$ & $1.5 \mathrm{~m} \mathrm{~s}^{-1}$ & $2.0 \mathrm{~m} \mathrm{~s}^{-1}$ \\
$1.4826 \cdot$ median absolute deviation & $2.6 \mathrm{~m} \mathrm{~s}^{-1}$ & $1.3 \mathrm{~m} \mathrm{~s}^{-1}$ & $1.8 \mathrm{~m} \mathrm{~s}^{-1}$ \\
\hline
\end{tabular}
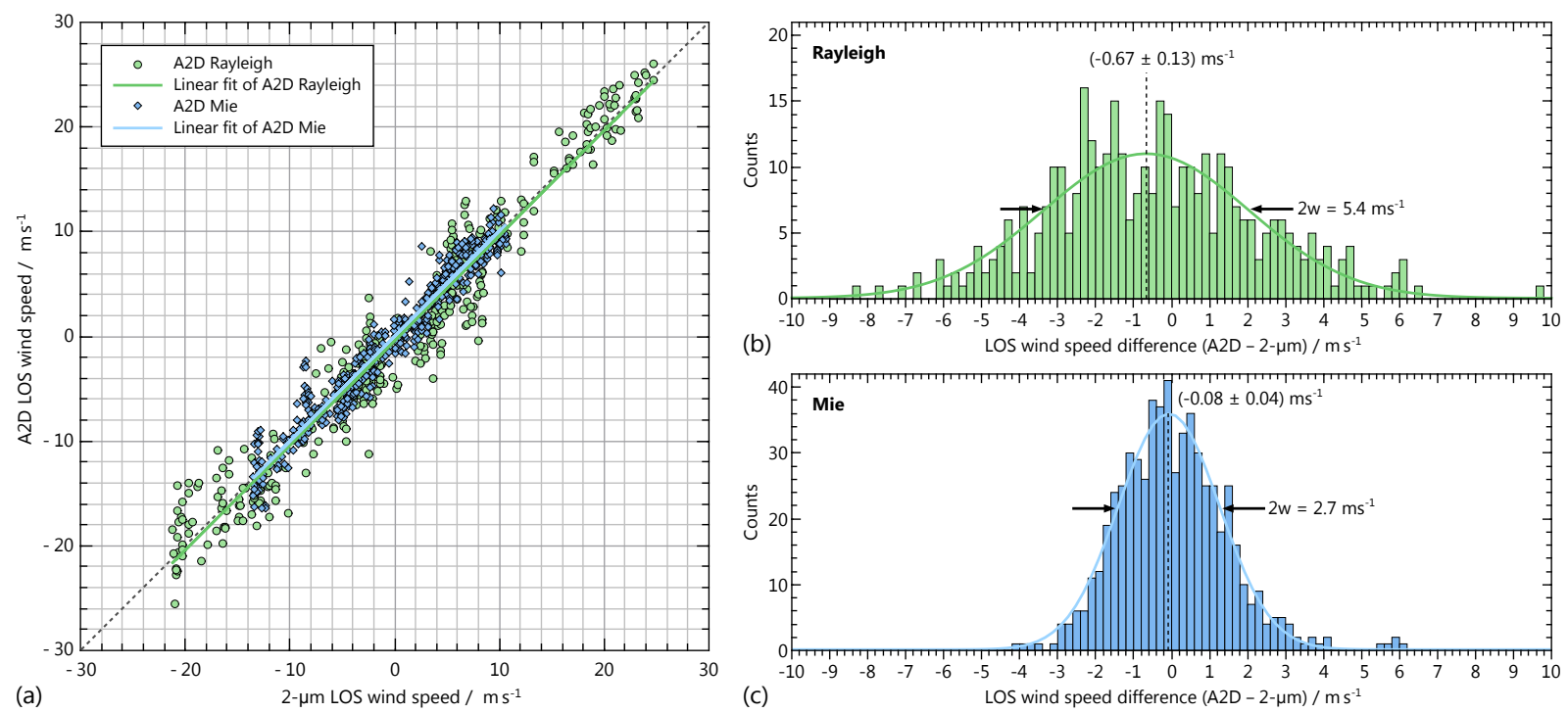

Figure 9. (a) A2D LOS wind speed determined with the Rayleigh (dots) and Mie (diamonds) channel versus the $2 \mu \mathrm{m}$ LOS wind speed for comparison of the wind data measured during the flight on 27 September 2016 between 10:28 and 12:36 UTC (see corresponding curtains in Fig. 7a, b and d). The scatterplot is obtained by adaptation of the different measurement grids of the two systems based on a weighted interpolation algorithm and a subsequent bin-to-bin comparison. The corresponding probability density functions for the wind differences (A2D-2 $\mu \mathrm{m}$ ) are shown in panels (b) and (c) for the Rayleigh and Mie channel, respectively. The solid lines represent Gaussian fits with the given centres and $e^{-1 / 2}$ widths $2 w$.

nel, the wind random error is nearly Gaussian-distributed, while a number of outliers with $v_{\mathrm{A} 2 \mathrm{D}}-v_{2 \mu \mathrm{m}} \approx 6 \mathrm{~m} \mathrm{~s}^{-1}$ leads to a discrepancy between the mean bias $\left(-0.03 \mathrm{~m} \mathrm{~s}^{-1}\right)$ and the centre of the Gaussian fit $\left(-0.08 \mathrm{~m} \mathrm{~s}^{-1}\right)$. For the same reason, the $e^{-1 / 2}$ width of the fit $\left(2 w=2.7 \mathrm{~m} \mathrm{~s}^{-1}\right)$ is narrower than twice the standard deviation $\left(2 \sigma=3.0 \mathrm{~m} \mathrm{~s}^{-1}\right)$, which also considers the outliers. Finally, due to the deviation from a Gaussian distribution, the scaled MAD of $1.3 \mathrm{~m} \mathrm{~s}^{-1}$ is slightly smaller than $\sigma$.

The random error of the Rayleigh channel is even larger $\left(\sigma=2.7 \mathrm{~m} \mathrm{~s}^{-1}\right)$. Like for the Mie channel, the PDF for the Rayleigh wind random error exhibits slight deviations from a Gaussian distribution. Consequently, the scaled MAD of $2.6 \mathrm{~m} \mathrm{~s}^{-1}$ marginally differs from the standard deviation $\sigma=2.7 \mathrm{~m} \mathrm{~s}^{-1}$.

\subsubsection{Discussion of Rayleigh and Mie wind errors}

Speckle noise was identified as one of the major causes for the increased random error of the A2D Rayleigh and Mie channel. The noise is introduced by the use of a fibre to transmit the internal reference signal from the laser to the front optics where it is injected into the receiver reception path and co-aligned with the atmospheric signal, as shown in Fig. 1. This is different compared to the free optical path setup in the transceiver of the satellite instrument which does not suffer this difficulty. The speckle pattern which was estimated to consist of about only 2000 speckles is the input for the Fizeau spectrometer and, after modification by reflection, also for the Fabry-Pérot spectrometers (DLR, 2016). Although the speckle pattern is static over short timescales 
of a few seconds to minutes, slow changes in the intensity distribution of the internal reference signal are introduced by variations in laser frequency, polarization or (ambient) fibre temperature, which in turn modify the response of the Mie and Rayleigh spectrometers. Since the response measured for the internal reference forms the basis for the determination of the Doppler frequency shift, and thus the wind speed in each atmospheric range gate, the speckle-induced fluctuations increase the random error over the entire wind profile. Comparisons of the internal reference frequencies derived from the Rayleigh and Mie responses against the frequencies measured using the wavemeter showed random variations $(2 \sigma)$ on the order of 8 (Mie) and $11 \mathrm{MHz}$ (Rayleigh), corresponding to LOS wind errors of 1.4 and $2.0 \mathrm{~m} \mathrm{~s}^{-1}$, respectively. Effective speckle reduction is envisaged, for example, by incorporating a moving diffuser into the beam path of the internal reference signal in order to rapidly change the speckle pattern within one observation, thus averaging out the variations.

Another contribution to the random error in the A2D Mie channel results from the combination of a heterogeneous cloud structure and strong wind shear, which is not resolved due to the coarse vertical resolution. In particular, the position of the top edges of optically thick clouds within one range gate has a significant influence on the wind data. According to Sun et al. (2014), who investigated the performance of Aeolus in heterogeneous atmospheric conditions using high-resolution radiosonde data, a non-uniform distribution of clouds and/or aerosols within a range bin introduces random errors in the Mie HLOS winds of several metres per second, depending on the bin size and altitude. This so-called height assignment error is especially large in the presence of strong wind shear in the sampling volume. Assuming a constant shear with typical amplitude of $0.01 \mathrm{~s}^{-1}$ over the bin, the Mie wind random error scales inversely proportional with the thickness of a particle layer randomly positioned inside the bin, reaching $2 \mathrm{~m} \mathrm{~s}^{-1}$ for a bin size of $1000 \mathrm{~m}$ and a layer thickness of $300 \mathrm{~m}$ (Sun et al., 2014).

Besides the speckle noise and the impact of the atmosphere, a further contribution to the random error of the Mie winds is caused by an imperfect response calibration procedure using a linear fitting function to describe the relationship between the Doppler frequency shift and the position of the fringe produced by the Fizeau interferometer. Hence, a more adequate fitting function will be applied in the future in order to take into account the Mie response nonlinearities and to improve the precision of the Mie channel.

Regarding the Rayleigh channel, the assessment of the precision and accuracy is complicated by the fact that the reference lidar relies on the presence of particles so that the statistical comparison of A2D Rayleigh winds with the $2 \mu \mathrm{m}$ DWL is limited to atmospheric regions, where cloud and aerosol backscattering occurs. Particulate backscattering leads to systematic errors of the Rayleigh winds since the convolution of the broadband Rayleigh return signal with the narrowband Mie return signal (Fig. 2a) influences the Rayleigh response according to Eq. (1) (Dabas et al., 2008). However, it should be noted that the $2 \mu \mathrm{m}$ DWL is very sensitive even to weak particulate backscatter return due to its coherent detection principle with small bandwidth. In addition, since the coherent DWL is deployed on the aircraft, the atmospheric altitudes with low aerosol backscatter are located in near range gates, which do not suffer remarkably from the $R^{2}$ dependency of the signal and strong aerosol extinction (as it would be the case for ground-based coherent DWL). Hence, $2 \mu \mathrm{m}$ DWL winds are even available for low scattering ratios $(<1.1)$, where a very small amount of aerosol contamination of the A2D Rayleigh winds can be expected. Moreover, Mie-contaminated bins in the Rayleigh data are identified by a signal threshold approach and excluded from the Rayleigh wind curtain, as explained in Sect. 4.1.2. Such range bins thus do not enter the statistical comparison with the $2 \mu \mathrm{m}$ DWL winds. Additionally, Rayleigh winds are disregarded in the case that valid winds are detected from the A2D Mie channel, i.e. if the Mie SNR threshold is exceeded (Sect. 4.1.3).

With a view to the Aeolus mission, it is also important to note that the strategy for vertical sampling differ between the A2D and the satellite instrument ALADIN. The latter will measure wind profiles from ground up to about $25 \mathrm{~km}$ altitude, so that the range gates covering the troposphere will generally be fewer and larger compared to the A2D where all the atmospheric range gates are available to sample the altitude range from ground up to about $9 \mathrm{~km}$. For the flights discussed in this work, the vertical sampling grid was chosen such that the wind shear in the jet stream region could be determined with the highest possible resolution. Hence, the A2D vertical sampling was adapted to the expected wind variability (from short-range NWP forecasts) and science objectives of the flights, which will not be possible for Aeolus where only a climatology-based approach for different vertical sampling schemes can be applied.

Apart from the speckle noise in the internal reference signal, the error contributions are different than for the Mie channel. The Rayleigh response calibration considers nonlinearities by using a fifth-order polynomial function for fitting the response curve. However, the measurement principle based on the double-edge technique using a sequential FPI is much more sensitive to angular variations of the backscattered light compared to the fringe-imaging technique employed in the Mie channel. As explained above, small angular fluctuations of $1 \mu \mathrm{rad}$ with respect to the $200 \mathrm{~mm}$ diameter telescope with a FOV of $100 \mu \mathrm{rad}$ introduce variations in the measured LOS wind speeds of about $0.4 \mathrm{~m} \mathrm{~s}^{-1}$ (DLR, 2016). Furthermore, the availability of $2 \mu \mathrm{m}$ wind data in those range bins that were used for the evaluation of the Rayleigh winds suggests at least a small contamination of the Rayleigh signal by particulate backscatter, thus introducing an increased random error (Dabas et al., 2008). 
In general, concerning systematic wind errors, a distinction has to be made between range-independent and rangedependent error sources. First, systematic errors are caused by inaccuracies in the aircraft attitude angles, e.g. by improper knowledge of the laser pointing, or by constant errors in the wind retrieval, e.g. introduced by uncertainties in the calibration parameters. The resulting wind bias is hence constant along the wind profile and can be reduced by applying ZWC, provided that sufficient ground return signals are available and that the atmospheric contamination of the ground return signals is low. If the latter conditions are not fulfilled, producing a wind-shear profile at the expense of one range bin is an option for eliminating this systematic error source in the analysis of the airborne observations. Similar systematic error sources, e.g. improper knowledge of pointing direction or satellite-induced LOS speed, exist for the satellite instrument producing a slowly varying bias along the orbit which will be not present in wind-shear profiles. Such errors can be compensated by means of ZWC.

The second class of systematic wind errors are rangedependent errors. One example which is specific to the A2D is the imperfect transmit-receive co-alignment, as discussed in Sect. 4.1.2. The error is largest in the near-field and decreases with increasing distance from the instrument, i.e. towards the ground. For the satellite instrument, the situation is more complicated due to the much higher ground track velocity of about $7.2 \mathrm{~km} \mathrm{~s}^{-1}$. The different travel times of laser pulses backscattered from different altitudes in combination with the angular movement of the satellite during the propagation period of the pulses leads to range-dependent incidence angles of the backscattered light on the Rayleigh and Mie spectrometers and hence to a range-dependent bias in the wind speeds. This effect will be characterized at the beginning of the Aeolus mission and can be subsequently corrected.

\subsection{Zero wind correction for the flight on 4 October 2016}

The wind scene on 27 September 2016 presented in the previous sections was characterized by optically dense clouds at different altitudes. As a consequence, the ground return signals detected during the scene were too weak for reliable determination of the ground speed which could be used for ZWC. Consequently, for this particular research flight, the refined ground detection scheme could not be exploited for reducing the systematic error of the Mie and Rayleigh wind speeds. Unfortunately, this circumstance holds true for most of the flights conducted in the context of NAWDEX, since the flight planning was primarily driven by the atmospheric science objectives of the campaign, resulting in complex atmospheric conditions with rather dense cloud coverage. One exception is the flight performed on 4 October 2016, which was dedicated to the investigation of the jet stream east of Iceland. For this purpose, the Falcon aircraft crossed the jet stream with increased wind speeds twice, as it flew two legs back and forth between the way points located at $66.0^{\circ} \mathrm{N}$, $17.5^{\circ} \mathrm{W}$ and $64.0^{\circ} \mathrm{N}, 7.0^{\circ} \mathrm{W}$ (see Fig. 10). To the west of the jet axis cloud-free conditions prevailed over the northeast of Iceland. Hence, high ground visibility was obtained at the beginning of the first leg and at the end of the second leg, as can be seen by the visible satellite image (MODIS, 2017b) a few hours after the flight depicted in Fig. 10a together with the flight track of the Falcon. The A2D measured wind profiles during the periods from 09:00 to 09:44 and from 09:54 to 10:30 UTC (see also Table 1). The figure reveals the contrasting atmospheric circumstances experienced during the flight which were characterized by highly variable cloud cover along the flight path.

Using the same Rayleigh and Mie response calibrations as for the flight on 27 September 2016, the results of the wind retrieval are displayed in Fig. 11. While the Rayleigh wind curtain shows good coverage at the beginning and the end of the period (Fig. 11a), valid Mie winds were primarily obtained in the vicinity of the jet stream centre, which was sampled in the middle of the flight (Fig. 11b). This again underlines the complementarity of the two channels which allows for excellent data coverage despite strongly diverse atmospheric conditions. Since the direction of the wind was towards the A2D LOS on the first leg, positive LOS wind speeds of up to $25 \mathrm{~m} \mathrm{~s}^{-1}$ (HLOS: $73 \mathrm{~m} \mathrm{~s}^{-1}$ ) were measured, whereas negative winds of the same magnitude were detected on the flight leg back to Iceland.

The systematic and random errors for the Rayleigh and Mie winds were determined from a statistical comparison with the $2 \mu \mathrm{m}$ reference wind lidar data. The resulting scatterplots and PDFs are shown in Fig. 12, while the statistical parameters are given in Table 5. Due to the poor overlap of the A2D Rayleigh wind data with the $2 \mu \mathrm{m}$ wind curtain (see Fig. 11d), only a small number of data points (168) entered the comparison despite a low coverage ratio threshold of $25 \%$. Consequently, the calculated mean bias $\left(1.54 \mathrm{~m} \mathrm{~s}^{-1}\right)$ and scaled MAD $\left(2.7 \mathrm{~m} \mathrm{~s}^{-1}\right)$ lack statistical significance. This also becomes obvious from the shape of the histogram illustrating the distribution of the Rayleigh wind errors (Fig. 12b), which strongly deviates from a Gaussian distribution. For this reason, the following discussion concentrates on the Mie channel. Here, a scaled MAD of $2.0 \mathrm{~m} \mathrm{~s}^{-1}$ was derived from the comparison with the reference lidar, which showed large data overlap with the Mie channel, resulting in 1246 compared bins. The mean bias of $0.57 \mathrm{~m} \mathrm{~s}^{-1}$ is considerably larger than the value obtained for the flight on 27 September 2016. The increase in systematic error might result from changes in the alignment of the transmit-receive path, which can slightly vary from flight to flight. In combination with potential inaccuracies in the aircraft attitude data, this leads to unknown contributions to the retrieved LOS wind speed which are not considered in the retrieval algorithm. 

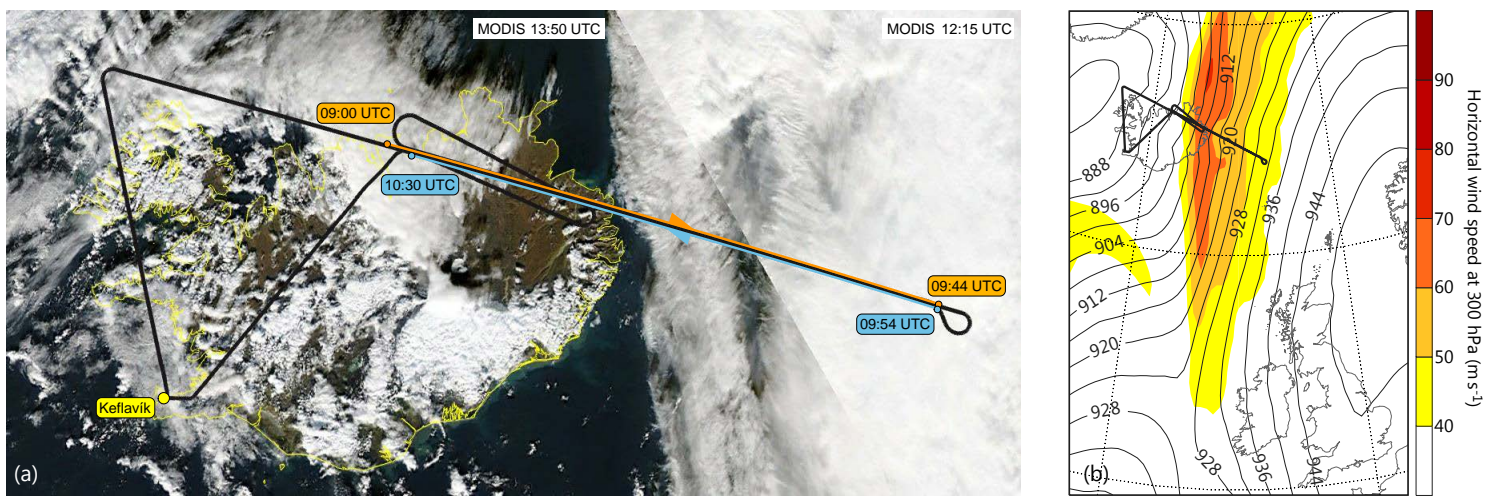

Figure 10. (a) Flight track of the Falcon aircraft (black line) during the research flight conducted on 4 October 2016. The wind scenes performed from 09:00 to 09:44 and from 09:54 to 10:30 UTC are indicated in orange and blue. High ground visibility was obtained over the northeast of Iceland at the beginning and the end of the scenes, respectively. The background picture is composed of a map provided by Google Earth and satellite images from Aqua MODIS (VIS channel) taken at 12:15 (right part) and 13:50 UTC (left part) (MODIS, 2017b). (b) Geopotential height (black isolines, in dekametres) and horizontal wind speed (colour shading) at 300 hPa over the North Atlantic on 4 October 2016, 12:00 UTC, from ECMWF model analysis together with the flight track of the Falcon 20 aircraft.

Table 5. Results of the statistical comparison between the A2D and the $2 \mu \mathrm{m}$ LOS wind data measured on 4 October 2016 . The statistical comparison for the Mie wind profiles was performed without and with ZWC.

\begin{tabular}{lrrr}
\hline Statistical parameter & Rayleigh winds & $\begin{array}{r}\text { Mie winds } \\
\text { (without ZWC) }\end{array}$ & $\begin{array}{r}\text { Mie winds } \\
\text { (with ZWC) }\end{array}$ \\
\hline Number of compared bins & 168 & 1246 & 1246 \\
Number of removed bins due to gross error $\left(> \pm 10 \mathrm{~m} \mathrm{~s}^{-1}\right.$ ) & 11 & 0 & 0 \\
Correlation coefficient $r$ & 0.96 & 0.99 & 0.99 \\
Slope $A$ & $1.01 \pm 0.02$ & $1.04 \pm 0.03$ & $1.04 \pm 0.03$ \\
Intercept $B$ & $1.67 \mathrm{~m} \mathrm{~s}^{-1}$ & $0.55 \mathrm{~m} \mathrm{~s}^{-1}$ & $0.02 \mathrm{~m} \mathrm{~s}^{-1}$ \\
Mean bias & $1.54 \mathrm{~m} \mathrm{~s}^{-1}$ & $0.57 \mathrm{~m} \mathrm{~s}^{-1}$ & $0.04 \mathrm{~m} \mathrm{~s}^{-1}$ \\
Standard deviation & $3.3 \mathrm{~m} \mathrm{~s}^{-1}$ & $1.9 \mathrm{~m} \mathrm{~s}^{-1}$ & $1.9 \mathrm{~m} \mathrm{~s}^{-1}$ \\
$1.4826 \cdot$ median absolute deviation & $2.7 \mathrm{~m} \mathrm{~s}^{-1}$ & $2.0 \mathrm{~m} \mathrm{~s}^{-1}$ & $2.0 \mathrm{~m} \mathrm{~s}^{-1}$ \\
\hline
\end{tabular}

The wind speed offset can, however, be reduced by ZWC based on the developed ground detection scheme. Any deviation from zero is interpreted as systematic error in the wind speed retrieval and hence subtracted from the measured wind speed. The ground speed (or ZWC) values obtained for the Mie channel during the two wind scenes on 4 October 2016 are plotted in Fig. 11c. From a total number of 268 observations, 59 observations included valid ZWC values in the ground range gates which were identified by the algorithm explained in Sect. 3.2. The respective observations are indicated as grey boxes in the Mie wind curtain. Thanks to the refined ground detection on measurement level, atmospheric contamination of the ground signals was minimized, thus ensuring that the detrimental influence of near-surface winds on the ZWC values was diminished. The mean of the ZWC values was determined to be $0.53 \mathrm{~m} \mathrm{~s}^{-1}$ with a standard deviation of $1.2 \mathrm{~m} \mathrm{~s}^{-1}$. The variation around the mean, which is also observed as random error in the atmospheric Mie wind speeds, can again be traced back to fluctuations in the Mie response measured for the internal reference. In order to confirm the correlation between the variability of the ZWC values and the internal reference variations, the Mie responses of the internal reference were converted to relative (laser) frequencies using the Mie response calibration. The obtained frequencies were compared to the frequencies measured with the high-precision wavemeter which tracked the absolute wavelength of the laser pulses emitted during the flight. The frequency difference (Mie response minus wavemeter) was finally translated into wind speed differences $\left(1 \mathrm{~m} \mathrm{~s}^{-1} \widehat{=} 5.63 \mathrm{MHz}\right)$, resulting in the dashed line plotted in Fig. 11c. The course of the curve is obviously correlated to the progression of the ZWC values, thus verifying that the noise in the internal reference considerably affects the measured ground speeds. As mentioned in the previous section, speckle noise is responsible for Mie response variations on the order of $\sigma=0.7 \mathrm{~m} \mathrm{~s}^{-1}$. Nevertheless, the mean value was used for correcting the Mie wind speeds, leading to the scatterplot depicted in Fig. 12a. The statistical parameters after ZWC are given in the right column Table 5. Subtraction of the mean $\mathrm{ZWC}$ value reduces the mean bias to $0.04 \mathrm{~m} \mathrm{~s}^{-1}$, 

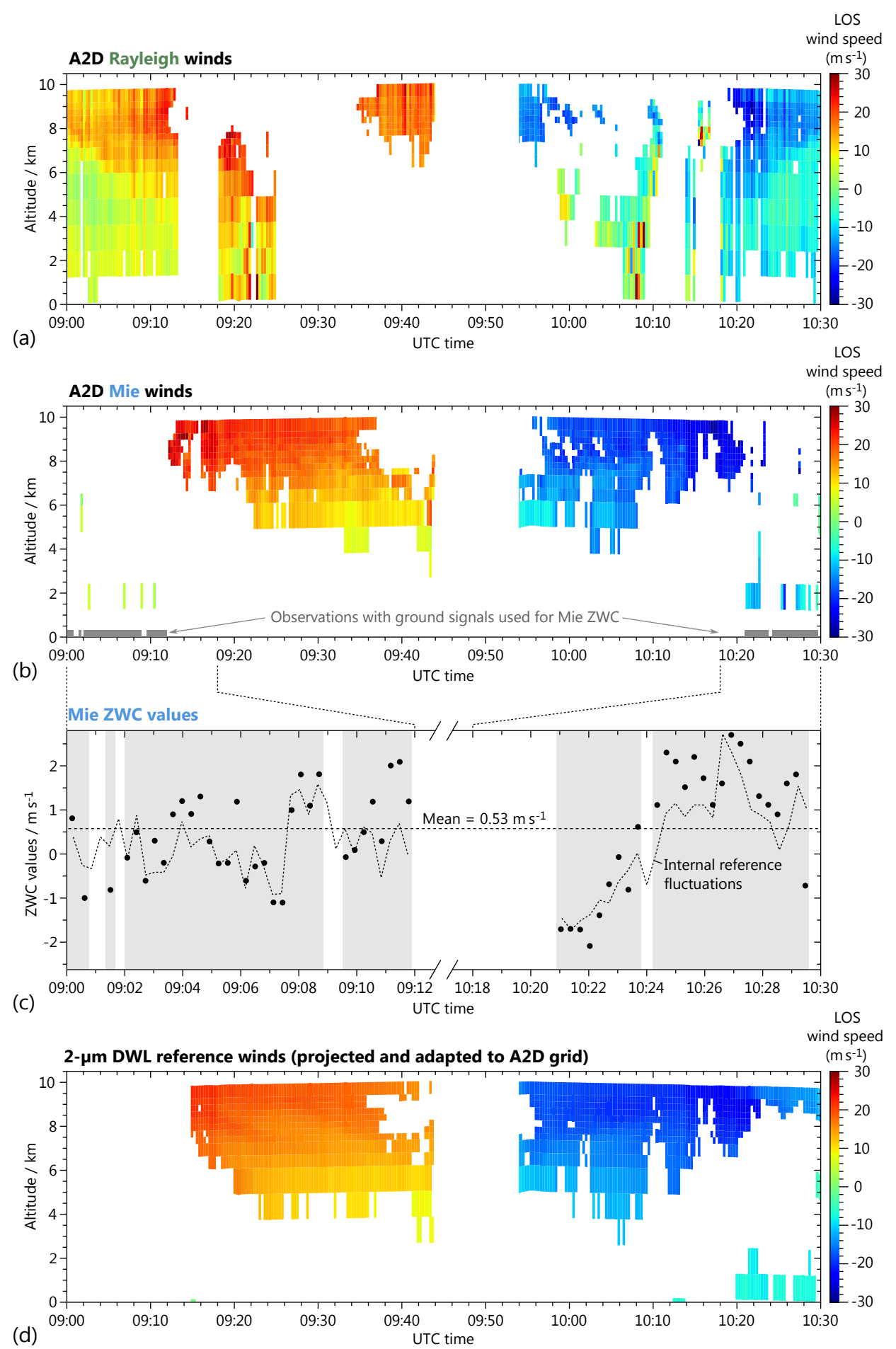

Figure 11. LOS wind profiles (positive towards the instrument) measured during the flight on 4 October 2016 between 09:00 and 10:30 UTC using (a) the A2D Rayleigh channel and (b) the A2D Mie channel. The grey boxes indicate periods during which the ground visibility was sufficient for obtaining ZWC data. The corresponding ZWC values are plotted in panel (c) together with the ground speed variations introduced by the Mie response fluctuations in the internal reference signals (see text). (d) Wind curtain measured with the coherent $2 \mu \mathrm{m}$ reference wind lidar. For better comparison, the $2 \mu \mathrm{m}$ wind data were adapted to the measurement grid of the A2D. The data gap between 09:44 and 09:54 UTC is due to an interruption of the wind measurement during a curve flight. 

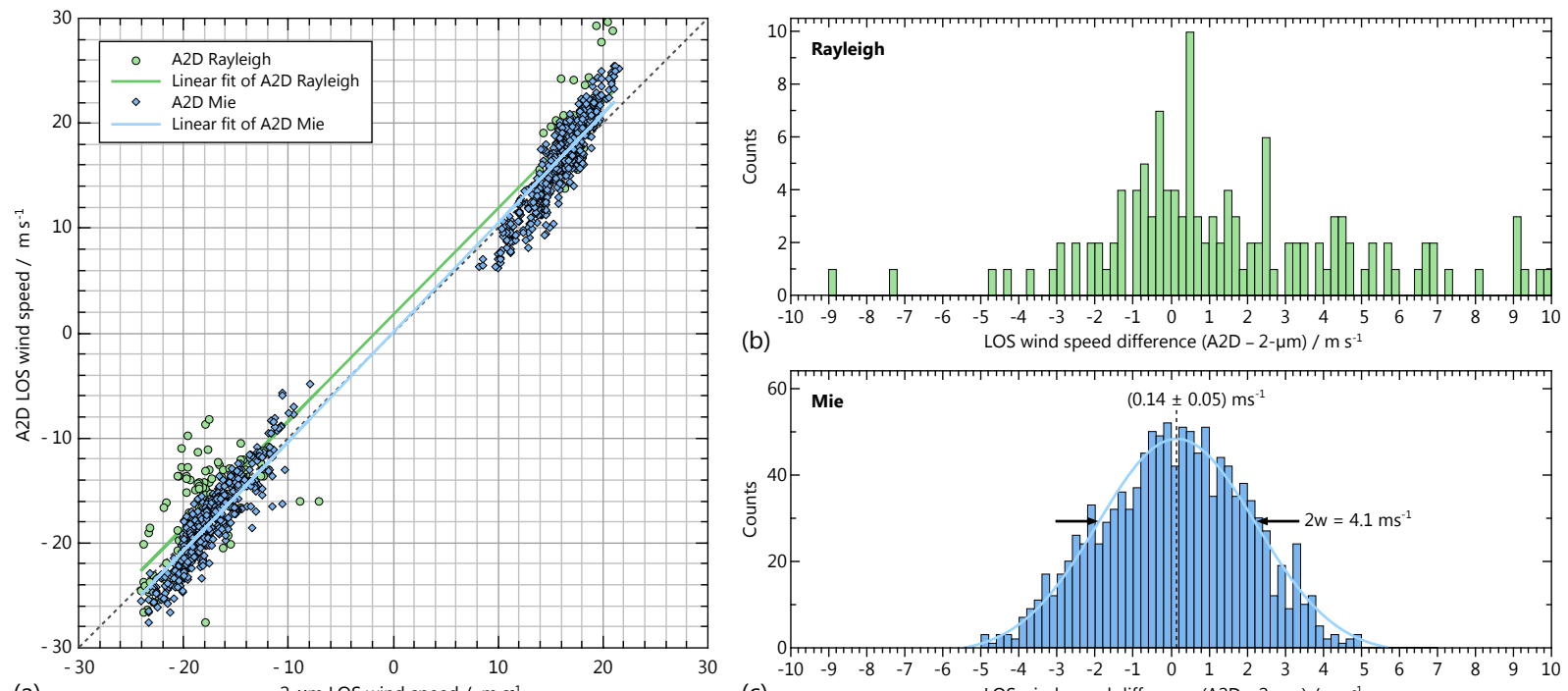

(a)

(b)

LOS wind speed difference (A2D - 2- $\mu \mathrm{m}) / \mathrm{m} \mathrm{s}^{-1}$

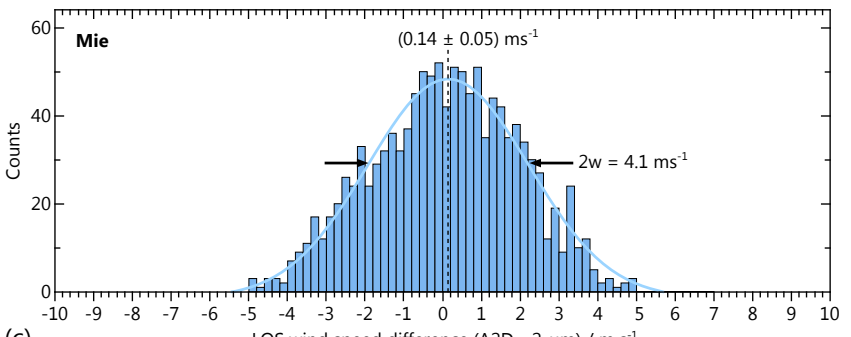

(c)

OS wind speed difference (A2D - 2- $\mu \mathrm{m}) / \mathrm{m} \mathrm{s}^{-1}$

Figure 12. (a) A2D LOS wind speed determined with the Rayleigh (dots) and Mie (diamonds) channel versus the $2 \mu \mathrm{m}$ LOS wind speed for comparison of the wind data measured during the flight on 4 October 2016 between 09:00 and 10:30 UTC (see corresponding curtains in Fig. 11a, b and d). The scatterplot for the Mie channel was obtained after zero wind correction was applied to the measured wind speeds. The corresponding probability density functions for the wind differences (A2D-2 $\mu \mathrm{m}$ ) are shown in panels (b) and (c) for the Rayleigh and Mie channel, respectively. The solid line represents a Gaussian fit with the given centre and $e^{-1 / 2}$ width $2 w$.

which is comparable to the result obtained for the flight on 27 September 2016. Hence, ZWC in combination with the refined ground detection scheme improves the accuracy of the A2D remarkably for the discussed flight.

\section{Summary and conclusion}

The ALADIN Airborne Demonstrator (A2D) represents an essential test bed for the validation of the upcoming Aeolus mission. Due to its similar and representative design and operation principle, the $\mathrm{A} 2 \mathrm{D}$ provides valuable information on the wind measurement strategies of the satellite instrument as well as on the optimization of the wind retrieval and related quality control algorithms. For this purpose, the A2D was successfully deployed for wind observations in the international airborne field campaign NAWDEX conducted in Iceland in autumn 2016. Within the scope of the campaign, 14 research flights were performed extending the wind and calibration dataset of the A2D for validating the retrieval algorithms and operation procedures. In particular, the recording of very high HLOS wind speeds above $80 \mathrm{~m} \mathrm{~s}^{-1}$ was obtained by sampling the North Atlantic jet stream, while the complementarity of the Rayleigh and Mie channel allowed for broad vertical and horizontal coverage across the troposphere.

Comparison of the A2D wind data with a high-resolution coherent Doppler wind lidar emitting at $2 \mu \mathrm{m}$ wavelength enabled the evaluation of the performance of the A2D in terms of accuracy and precision. For the flight on 27 September 2016, the mean bias was found to be $-0.49 \mathrm{~m} \mathrm{~s}^{-1}$ for the
Rayleigh channel and $-0.03 \mathrm{~m} \mathrm{~s}^{-1}$ for the Mie channel. A larger Mie wind speed bias of $0.57 \mathrm{~m} \mathrm{~s}^{-1}$ was determined for the flight on 4 October 2016, but could be reduced to $0.04 \mathrm{~m} \mathrm{~s}^{-1}$ by means of ZWC. The latter was supported by accurate ground detection using a scheme that minimizes the contribution of atmospheric return signals in the identified ground range gates. This method was also implemented in the analysis of the Rayleigh and Mie response calibrations where it is particularly effective in case of low-albedo surfaces in the UV (e.g. land) or areas with strongly varying ground elevations. The ground detection scheme is envisaged to be fully exploited in upcoming airborne campaigns to provide accurate ZWC for flights with sufficient ground visibility. In order to reduce the random error both in the detected ground speeds and in the atmospheric wind speeds, the response fluctuations in the internal reference signals need to be diminished. This problem, which is absent in the satellite instrument, is proposed to be solved by avoiding slow variations in the speckle pattern incident on the Mie and Rayleigh spectrometers, e.g. by implementing a fast diffuser.

In addition to the internal reference fluctuations, the large random errors of about $2.7 \mathrm{~m} \mathrm{~s}^{-1}$ in the Rayleigh channel can be traced back to the transmit-receive path co-alignment in combination with the high incidence angle sensitivity of the Rayleigh spectrometer, while the heterogeneity of the atmosphere and the nonlinearity of the Mie response function are considered to be additional factors contributing to the random error $\left(1.5 \mathrm{~m} \mathrm{~s}^{-1}\right)$ observed for the Mie winds. Hence, apart from the technical development of the A2D regarding speckle reduction and improved co-alignment, the main fo- 
cus of the current research is on the improvement of the system accuracy and precision by implementing a novel Mie response calibration procedure considering nonlinearities. The modifications of the A2D are intended to be tested in the frame of forthcoming airborne campaigns which will also aim to conduct flights in coordination with the Aeolus satellite after its launch in 2018.

Data availability. Data used in this paper can be provided upon request by email to Oliver Reitebuch (oliver.reitebuch@dlr.de).

Competing interests. The authors declare that they have no conflict of interest.

Acknowledgements. The development of the ALADIN Airborne Demonstrator and the work carried out during the NAWDEX campaign were supported by the German Aerospace Center (Deutsches Zentrum für Luft- und Raumfahrt e.V., DLR) and the European Space Agency (ESA), providing funds related to the preparation of Aeolus (WindVal II, contract no. 4000114053/15/NL/FF/gp), as well as NRL Monterrey and the EUropean Facility for Airborne Research (EUFAR, project NAWDEX Influence). The first author was partly funded by a young scientist grant by ESA within the DRAGON 4 program (contract no. 4000121191/17/I-NB). The authors are especially grateful to Engelbert Nagel for his constant support throughout the campaign.

The article processing charges for this open-access publication were covered by a Research

Centre of the Helmholtz Association.

Edited by: Ad Stoffelen

Reviewed by: Gert-Jan Marseille and Mike Hardesty

\section{References}

Amediek, A. and Wirth, M.: Pointing Verification Method for Spaceborne Lidars, Remote Sens., 9, 56, https://doi.org/10.3390/rs9010056, 2017.

Andersson, E.: Statement of Guidance for Global Numerical Weather Prediction (NWP), World Meteorological Organisation, available at: https://www.wmo.int/pages/prog/www/OSY/SOG/ SoG-Global-NWP.pdf (last access: 25 October 2017), 2016.

Ansmann, A., Wandinger, U., Le Rille, O., Lajas, D., and Straume, A. G.: Particle backscatter and extinction profiling with the spaceborne high-spectral-resolution Doppler lidar ALADIN: Methodology and simulations, Appl. Opt., 46, 6606-6622, https://doi.org/10.1364/AO.46.006606, 2007.

Baker, W. E., Atlas, R., Cardinali, C., Clement, A., Emmitt, G. D., Gentry, B. M., Hardesty, R. M., Källén, E., Kavaya, M. J., Langland, R., Ma, Z., Masutani, M., McCarty, W., Pierce, R. B., Pu, Z., Riishojgaard, L. P., Ryan, J., Tucker, S., Weissmann, M., and Yoe, J. G.: Lidar-Measured Wind Profiles: The Missing Link in the Global Observing System, B. Am. Meteorol. Soc., 95, 543564, https://doi.org/10.1175/BAMS-D-12-00164.1, 2014.

Banakh, V. A., Smalikho, I. N., and Rahm, S.: Estimation of the refractive index structure characteristic of air from coherent Doppler wind lidar data, Opt. Lett., 39, 4321-4324, https://doi.org/10.1364/OL.39.004321, 2014.

Baumgarten, G.: Doppler Rayleigh/Mie/Raman lidar for wind and temperature measurements in the middle atmosphere up to $80 \mathrm{~km}$, Atmos. Meas. Tech., 3, 1509-1518, https://doi.org/10.5194/amt-3-1509-2010, 2010.

Berry, P. A. M., Smith, R. G., and Benveniste, J.: ACE2: The New Global Digital Elevation Model, in: Gravity, Geoid and Earth Observation, edited by: Mertikas, S. P., International Association of Geodesy Symposia, Springer Berlin, Heidelberg, 231-237, 2010.

Bosart, B. L., Lee, W.-C., and Wakimoto, R. M.: Procedures to Improve the Accuracy of Airborne Doppler Radar Data, J. Atmos. Ocean. Tech., 19, 322-339, https://doi.org/10.1175/1520-042619.3.322, 2002.

Chanin, M. L., Garnier, A., Hauchecorne, A., and Porteneuve, J.: A Doppler lidar for measuring winds in the middle atmosphere, Geophys. Res. Lett., 16, 1273-1276, https://doi.org/10.1029/GL016i011p01273, 1989.

Chouza, F., Reitebuch, O., Jähn, M., Rahm, S., and Weinzierl, B.: Vertical wind retrieved by airborne lidar and analysis of island induced gravity waves in combination with numerical models and in situ particle measurements, Atmos. Chem. Phys., 16, 46754692, https://doi.org/10.5194/acp-16-4675-2016, 2016a.

Chouza, F., Reitebuch, O., Benedetti, A., and Weinzierl, B.: Saharan dust long-range transport across the Atlantic studied by an airborne Doppler wind lidar and the MACC model, Atmos. Chem. Phys., 16, 11581-11600, https://doi.org/10.5194/acp-16-115812016, 2016 b.

Dabas, A., Denneulin, M. L., Flamant, P., Loth, C., Garnier, A., and Dolfi-Bouteyre, A.: Correcting winds measured with a Rayleigh Doppler lidar from pressure and temperature effects, Tellus A, 60, 206-215, https://doi.org/10.1111/j.1600-0870.2007.00284.x, 2008.

Deutsches Zentrum für Luft- und Raumfahrt e.V. (DLR): Final Report: Analysis of enhanced noise in A2D observations, AE.FR.DLR.A2D.CN11.110716, V 2.0, 110 pp., 2016.

Dolfi-Bouteyre, A., Canat, G., Valla, M., Augere, B., Besson, C., Goular, D., Lombard, L., Cariou, J.-P., Durecu, A., Fleury, D., Bricteux, L., Brousmiche, S., Lugan, S., and Macq, B.: Pulsed 1.5 $\mu \mathrm{m}$ LIDAR for Axial Aircraft Wake Vortex Detection Based on High-Brightness Large-Core Fiber Amplifier, IEEE J. Sel. Top. Quant., 15, 441-450, https://doi.org/10.1109/JSTQE.2008.2010463, 2009.

Dou, X., Han, Y., Sun, D., Xia, H., Shu, Z., Zhao, R., Shangguan, M., and Guo, J.: Mobile Rayleigh Doppler lidar for wind and temperature measurements in the stratosphere and lower mesosphere, Opt. Express, 22, A1203-A1221, https://doi.org/10.1364/OE.22.0A1203, 2014.

European Space Agency (ESA): ADM-Aeolus Science Report, ESA SP-1311, 121 pp., available at: http://esamultimedia.esa.int/ docs/SP-1311_ADM-Aeolus_FINAL_low-res.pdf (last access: 21 August 2017), 2008.

European Space Agency (ESA): ADM-Aeolus Mission Requirements Document, ESA EOP-SM/2047, 57 pp., avail- 
able at: http://esamultimedia.esa.int/docs/EarthObservation/ ADM-Aeolus_MRD.pdf (last access: 4 March 2018), 2016.

ISO 11146-1:2005(E): Lasers and laser-related equipment - Test methods for laser beam widths, divergence angles and beam propagation ratios, 2005.

Flamant, P., Cuesta, J., Denneulin, M. L., Dabas, A., and Huber, D.: ADM-Aeolus retrieval algorithms for aerosol and cloud products, Tellus A, 60, 273-288, https://doi.org/10.1111/j.16000870.2007.00287.x, 2008.

Flesia, C. and Korb, C. L.: Theory of the double-edge molecular technique for Doppler lidar wind measurement, Appl. Opt., 38, 432-440, https://doi.org/10.1364/AO.38.000432, 1999.

Garnier, A. and Chanin, M. L.: Description of a Doppler Rayleigh LIDAR for measuring winds in the middle atmosphere, Appl. Phys. B, 55, 35-40, https://doi.org/10.1007/BF00348610, 1992.

Gentry, B. M., Chen, H., and Li, S. X.: Wind measurements with 355-nm molecular Doppler lidar, Opt. Lett., 25, 1231-1233, https://doi.org/10.1364/OL.25.001231, 2000.

Hildebrand, J., Baumgarten, G., Fiedler, J., Hoppe, U.-P., Kaifler, B., Lübken, F.-J., and Williams, B. P.: Combined wind measurements by two different lidar instruments in the Arctic middle atmosphere, Atmos. Meas. Tech., 5, 2433-2445, https://doi.org/10.5194/amt-5-2433-2012, 2012.

Kavaya, M. J., Beyon, J. Y., Koch, G. J., Petros, M., Petzar, P. J., Singh, U. N., Trieu, B. C., and Yu, J.: The Doppler Aerosol Wind (DAWN) Airborne, Wind-Profiling Coherent-Detection Lidar System: Overview and Preliminary Flight Results, J. Atmos. Ocean. Tech., 31, 826-842, 2014.

Köpp, F., Rahm, S., and Smalikho, I.: Characterization of Aircraft Wake Vortices by $2 \mu \mathrm{m}$ Pulsed Doppler Lidar, J. Atmos. Ocean. Tech., 21, 194-206, https://doi.org/10.1175/15200426(2004)021<0194:COAWVB>2.0.CO;2, 2004.

Lemmerz, C., Lux, O., Reitebuch, O., Witschas, B., and Wührer, C.: Frequency and timing stability of an airborne injection-seeded Nd: YAG laser system for direct-detection wind lidar, Appl. Opt., 56, 9057-9068, https://doi.org/10.1364/ao.56.009057, 2017.

Li, Z., Lemmerz, C., Paffrath, U., Reitebuch, O., and Witschas, B.: Airborne Doppler Lidar Investigation of Sea Surface Reflectance at a 355-nm Ultraviolet Wavelength, J. Atmos. Ocean. Tech., 27, 693-704, https://doi.org/10.1175/2009JTECHA1302.1, 2010.

Marksteiner, U., Reitebuch, O., Rahm, S., Nikolaus, I., Lemmerz, C., and Witschas, B.: Airborne direct-detection and coherent wind lidar measurements along the east coast of Greenland in 2009 supporting ESA's Aeolus mission, Proc. SPIE, 8182, 81820J, https://doi.org/10.1117/12.897528, 2011.

Marksteiner, U.: Airborne Wind Lidar Observations for the Validation of the ADM-Aeolus Instrument, $\mathrm{PhD}$ thesis, Technische Universität München, 180 pp., available at: http://mediatum.ub. tum.de?id=1136781 (last access: 28 August 2017), 2013.

Marksteiner, U., Reitebuch, O., Lemmerz, C., Lux, O., Rahm, S., Witschas, B., Schäfler, A., Emmitt, D., Greco, S., Kavaya, M. J., Gentry, B., Neely III, B. R., Kendall, E., and Schüttemeyer, D.: Airborne Direct-Detection and Coherent Wind Lidar Measurements over the North Atlantic in 2015 Supporting ESA's Aeolus Mission, Proc. 28th International Laser-Radar Conference, Bucharest, Romania, 25-30 June, 2017.

McKay, J. A.: Assessment of a multibeam Fizeau wedge interferometer for Doppler wind lidar, Appl. Opt., 41, 1760-1767, https://doi.org/10.1364/AO.41.001760, 2002.
MODIS: Iceland 2 Subset - Terra 1 km True Color 2016/271 (09/27), available at: https://lance-modis.eosdis.nasa.gov/ imagery/subsets/?subset=Iceland2.2016271.terra.1km, last access: 8 December 2017a.

MODIS: Iceland 2 Subset - Aqua 1 km True Color 2016/278 (10/04), available at: https://lance-modis.eosdis.nasa.gov/ imagery/subsets/?subset=Iceland2.2016278.aqua.1km, last access: 4 December $2017 b$.

Nicklaus, K., Morasch, V., Hoefer, M., Luttmann, J., Vierkötter, M., Ostermeyer, M., Höffner, J., Lemmerz, C., Hoffmann, D., Hoffman, H. J., Shori, R., and Hodgson, N.: Frequency stabilization of Q-switched Nd:YAG oscillators for airborne and spaceborne lidar systems, Proc. SPIE, 6451, 64511L, https://doi.org/10.1117/12.701187, 2007.

Paffrath, U.: Performance assessment of the Aeolus Doppler wind lidar prototype, $\mathrm{PhD}$ thesis, Technische Universität München, 144 pp., available at: https://mediatum.ub.tum.de/?id=601980 (last access: 23 June 2017), 2006.

Paffrath, U., Lemmerz, C., Reitebuch, O., Witschas, B., Nikolaus, I., and Freudenthaler, V.: The Airborne Demonstrator for the Direct-Detection Doppler Wind Lidar ALADIN on ADMAeolus. Part II: Simulations and Rayleigh Receiver Radiometric Performance, J. Atmos. Ocean. Tech., 26, 2516-2530, https://doi.org/10.1175/2009JTECHA1314.1, 2009.

Reitebuch, O.: Wind Lidar for Atmospheric Research, in: Atmospheric physics: Background, methods, trends, edited by: Schumann, U., Research Topics in Aerospace, Springer, Berlin, London, 487-507, 2012a.

Reitebuch, O.: The Spaceborne Wind Lidar Mission ADM-Aeolus, in: Atmospheric physics: Background, methods, trends, edited by: Schumann, U., Research Topics in Aerospace, Springer, Berlin, London, 815-827, 2012b.

Reitebuch, O., Lemmerz, C., Nagel, E., Paffrath, U., Durand, Y., Endemann, M., Fabre, F., and Chaloupy, M.: The Airborne Demonstrator for the Direct-Detection Doppler Wind Lidar ALADIN on ADM-Aeolus. Part I: Instrument Design and Comparison to Satellite Instrument, J. Atmos. Ocean. Tech., 26, 2501-2515, https://doi.org/10.1175/2009JTECHA1309.1, 2009.

Reitebuch, O., Marksteiner, U., Rompel, M., Meringer, M., Schmidt, K., Huber, D., Nikolaus, I., Dabas, A., Marshall, J., de Bruin, F., Kanitz, T., and Straume, A.-G.: Aeolus End-to-End Simulator and Wind Retrieval Algorithms up to Level 1B, Proc. 28th International Laser-Radar Conference (ILRC), Bucharest, Romania, 25-30 June, 2017.

Reitebuch, O., Huber, D., and Nikolaus, I.: ADM-Aeolus Algorithm Theoretical Basis Document (ATBD) Level1B Products, AE-RPDLR-L1B-001, 4.4, 117 pp., 2018.

Schäfler, A., Craig, G., Wernli, H., Arbogast, P., Doyle, J. D., McTaggart-Cowan, R., Methven, J., Rivière, G., Ament, F., Boettcher, M., Bramberger, M., Cazenave, Q., Cotton, R., Crewell S., Delanoë, J., Dörnbrack, A., Ehrlich, A., Ewald, F., Fix, A., Grams, C. M., Gray, S. L., Grob, H., Groß, S., Hagen, M., Harvey, B., Hirsch, L., Jacob, M., Kölling, T., Konow, H., Lemmerz, C., Lux, O., Magnusson, L., Mayer, B., Mech, M., Moore, R., Pelon, J., Quinting, J., Rahm, S., Rapp, M., Rautenhaus, M., Reitebuch, O., Reynolds, C. A., Sodemann, H., Spengler, T., Vaughan, G., Wendisch, M., Wirth, M., Witschas, B., Wolf, K., and Zinner, T.: The North Atlantic Waveguide and Down- 
stream Impact Experiment, B. Am. Meteorol. Soc., in press, https://doi.org/10.1175/BAMS-D-17-0003.1, 2018.

Schröder, T., Lemmerz, C., Reitebuch, O., Wirth, M., Wührer, C., and Treichel, R.: Frequency jitter and spectral width of an injection-seeded Q-switched Nd:YAG laser for a Doppler wind lidar, Appl. Phys. B, 87, 437-444, https://doi.org/10.1007/s00340-007-2627-5, 2007.

Shangguan, M., Xia, H., Wang, C., Qiu, J., Lin, S., Dou, X., Zhang, Q., and Pan, J.-W.: Dual-frequency Doppler lidar for wind detection with a superconducting nanowire single-photon detector, Opt. Lett., 42, 3541-3544, https://doi.org/10.1364/OL.42.003541, 2017.

Stoffelen, A., Pailleux, J., Källen, E., Vaughan, M., Isaksen, L., Flamant, P., Wergen, W., Andersson, E., Schyberg, H., Culoma, A., Meynart, R., Endemann, M., and Ingmann, P.: The Atmospheric Dynamics Mission for Global Wind Field Measurement, B. Am. Meteorol. Soc. 86, 73-87, https://doi.org/10.1175/BAMS-86-173, 2005.

Sun, X. J., Zhang, R. W., Marseille, G. J., Stoffelen, A., Donovan, D., Liu, L., and Zhao, J.: The performance of Aeolus in heterogeneous atmospheric conditions using highresolution radiosonde data, Atmos. Meas. Tech., 7, 2695-2717, https://doi.org/10.5194/amt-7-2695-2014, 2014.

Tan, D. G. H. and Andersson, E.: Simulation of the yield and accuracy of wind profile measurements from the Atmospheric Dynamics Mission (ADM-Aeolus), Q. J. Roy. Meteor. Soc., 131, 1737-1757, https://doi.org/10.1256/qj.04.02, 2005.

Tan, D. G. H., Andersson, E., Kloe, J. D., Marseille, G.-J., Stoffelen, A., Poli, P., Denneulin, M.-L., Dabas, A., Huber, D., Reitebuch, O., Flamant, P., Le Rille, O., and Nett, H.: The ADM-Aeolus wind retrieval algorithms, Tellus A, 60, 191-205, https://doi.org/10.1111/j.1600-0870.2007.00285.x, 2016.
Weiler, F.: Bias correction using ground echoes for the airborne demonstrator of the wind lidar on the ADM-Aeolus mission, Master's thesis, University of Innsbruck, 96 pp., available at: https://resolver.obvsg.at/urn:nbn:at:at-ubi:1-7104 (last access: 11 October 2017), 2017.

Weissmann, M., Busen, R., Dörnbrack, A., Rahm, S., and Reitebuch, O.: Targeted Observations with an Airborne Wind Lidar, J. Atmos. Ocean. Tech., 22, 1706-1719, https://doi.org/10.1175/JTECH1801.1, 2005.

Witschas, B.: Analytical model for Rayleigh-Brillouin line shapes in air, Appl. Opt., 50, 267-270, https://doi.org/10.1364/AO.50.000267, 2011a.

Witschas, B.: Analytical model for Rayleigh-Brillouin line shapes in air: Errata, Appl. Opt., 50, 5758, https://doi.org/10.1364/AO.50.005758, 2011b.

Witschas, B.: Experiments on spontaneous Rayleigh-Brillouin scattering in air, $\mathrm{PhD}$ thesis, Friedrich-Schiller-Universität, Jena, 112 pp., available at: http://elib.dlr.de/98547/ (last access: 8 March 2017), 2011c.

Witschas, B., Lemmerz, C., and Reitebuch, O.: Daytime measurements of atmospheric temperature profiles $(2-15 \mathrm{~km})$ by lidar utilizing Rayleigh-Brillouin scattering, Opt. Lett., 39, 1972-1975, https://doi.org/10.1364/OL.39.001972, 2014.

Witschas, B., Rahm, S., Dörnbrack, A., Wagner, J., and Rapp, M.: Airborne Wind Lidar Measurements of Vertical and Horizontal Winds for the Investigation of Orographically Induced Gravity Waves, J. Atmos. Ocean. Tech., 34, 1371-1386, https://doi.org/10.1175/JTECH-D-17-0021.1, 2017. 